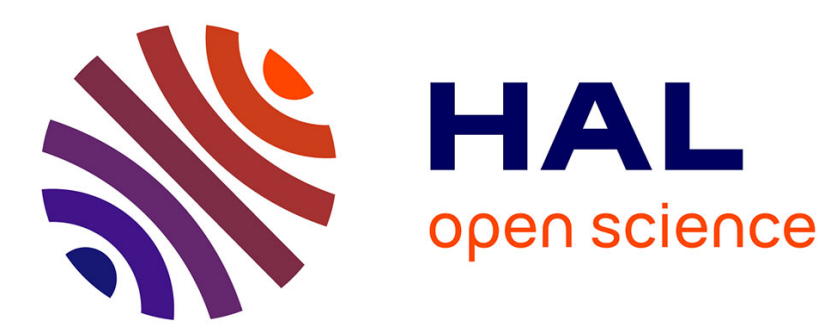

\title{
Are traditional industrial partnerships so strategic for research spin-off development? Some evidence from the Italian case
}

Pierre-Jean Benghozi, Elisa Salvador

\section{- To cite this version:}

Pierre-Jean Benghozi, Elisa Salvador. Are traditional industrial partnerships so strategic for research spin-off development? Some evidence from the Italian case. Entrepreneurship and Regional Development, 2014, 10.1080/08985626.2013.860194 . hal-02091032

\section{HAL Id: hal-02091032 \\ https://hal.science/hal-02091032}

Submitted on 5 Apr 2019

HAL is a multi-disciplinary open access archive for the deposit and dissemination of scientific research documents, whether they are published or not. The documents may come from teaching and research institutions in France or abroad, or from public or private research centers.
L'archive ouverte pluridisciplinaire HAL, est destinée au dépôt et à la diffusion de documents scientifiques de niveau recherche, publiés ou non, émanant des établissements d'enseignement et de recherche français ou étrangers, des laboratoires publics ou privés. 
This article has been accepted by the Journal

\title{
Entrepreneurship \& Regional Development: an International Journal
}

\author{
It can be cited as follows:
}

Benghozi P.-J., Salvador E. (2014) “Are traditional industrial partnerships so strategic for research spinoff development? Some evidence from the Italian case", Entrepreneurship\&Regional Development: an International Journal, vol. 26 (1-2): 47-79. This article has been included in the online article collection as one of the most downloaded articles published in Routledge Social Sciences journals in 2014.

\section{“Are traditional industrial partnerships so strategic for research spin-off development? Some evidence from the Italian case"}

\begin{abstract}
This paper aims to contribute to the literature on research spin-offs and strategic alliances. The research spin-off phenomenon has attracted significant attention in recent years. Yet research spin-offs might present a particular situation regarding their economic development. Therefore, the paper focuses on the relevance of traditional industrial partnerships and introduces a new and complementary approach for studying and analysing the role of alliances for this particular kind of firm. The results of a questionnaire investigation of Italian research spin-offs with and without a traditional industrial partner are investigated and supported by a linear regression model. Due to recent initiatives -a growing interest in the research spinoff phenomenon - and the increasing number of established research spin-offs, Italy is a suitable case-study for such an investigation. Nonetheless, the results are generalizable beyond the Italian case. The findings demonstrate thought-provoking - and somehow unexpected - results regarding the role of traditional alliances in shaping the geographical and industrial environment as well as the performance, added value, age, and production process of the company. This calls for a broader perspective regarding industrial partnerships and research spin-offs: it reflects new modes of relations for these particular firms in the form of business ecosystems, either they are physical or digital.
\end{abstract}

JEL Codes: O3; L2

Keywords: research spin-offs; partnerships; science parks; technology transfer; networking; business ecosystems; digital business ecosystems 


\section{Introduction}

In recent years, the research spin-off (SO) phenomenon has gained increasing attention and is considered to be one of the main tools for the exploitation of university research results. The literature on SO "has been growing in dispersed directions" (Gilsing et al., 2010, p. 12), and SO "remains a vaguely defined concept" (Bathelt et al., 2010, p. 520). This on the one hand constrains the analysis on this field, while on the other it motivates further investigation of several aspects surrounding this particular kind of firm.

However, their recency and small size prevent SO from obtaining all the required talents. Consequently, these firms are expected to call for strong and intense partnerships, as hypothesized by existing industrial policies. $R \& D$ and entrepreneurship literature suggest industrial partnerships as one possible solution for enabling SO to compensate for weaknesses in key aspects of their development (e.g. management and business competencies, industrial productivity). In recent years Wright et al. (2004, 2007) highlighted potential advantages of a joint venture with an industrial partner. According to this study, the creation of a SO as a joint venture with an industrial partner could potentially solve problems associated with managing weak resources and/or inadequate capabilities. With a focus on joint venture spin-offs (JVSO) ${ }^{1}$, Wright et al. $(2004 ; 2007)$ have been among the first contributors to the literature in this field and have emphasized the need for further investigation of the potential downsides ${ }^{2}$ of such collaborations. In a recent comparison between academic and non-academic high-tech start-ups, Colombo and Piva (2012) examined the effects of genetic firm characteristics and their effects on post-entry strategies in a comparison between academic and non-academic high-tech start-ups, taking into account the role of alliances.

The aim of this paper is to investigate whether structural changes in ICT-related technological development, combined with the growing importance of new forms of industrial clusters, are indicative of an evolution in the nature of industrial partnerships and the ways in which they are used by SO.

As highlighted by Hagedoorn et al. (2000, p. 568), "there is no uniformly accepted definition of partnership in the academic or technology policy literature”. Descriptions of traditional industrial partnerships extend beyond a mere producer-supplier relationship to suppose that partners cooperate in the development of common projects and reciprocally share knowledge for joint value creation. In this paper, we therefore use the broad terms "partnership", "alliance", and "cooperation" as synonyms, and we define them to be a formal, interorganizational, mutually beneficial agreement between two or more organisations that cooperate and join resources/knowledge/capabilities/interests in order to achieve specific goals (Yasuda, 2005). Beyond this traditional perspective, particular kinds of firms like SO need more feasible and suitable relations, due to their strong scientific and technical knowledge background, and disruptive skills, supporting both tacit and codified knowledge. Therefore, they call for new types of partnerships. As a consequence, the issue of industrial partnership is of particular importance for SO because of their specific nature. Universities

\footnotetext{
${ }^{1}$ According to Wright et al. (2004, p. 288) “A JVSO is a new venture in which technology is assigned or licensed into a new company that is jointly owned by the university and the industrial partner".

${ }^{2}$ In particular, "We could caution, however, that a potential downside is the need to put mechanisms in place to control the joint venture partner and to select a partner with compatible objectives and expertise", (Wright et al., 2007, p. 125 and Wright et al., 2004, p. 308).
} 
may have scientists with a comparative advantage in the invention of a new technology, but they may lack people with product development skills and business knowledge (Shane, 2004; Colombo, Piva, 2012). Such situations have led to gaps in finance and management competence as well as in the credibility of the market (Wright et al., 2007; Mustar et al., 2008). SO lack the market knowledge and business experience needed to transform their knowledge into a profitable product (Harrison, Leitch, 2010; Clarysse et al., 2011; Iacobucci et al., 2011). In combination with the poor performance usually observed in SO (Mustar et al., 2008; van Geenhuizen, Soetanto, 2009; Bathelt et al., 2010), these findings suggest that a learning process and/or a traditional industrial partnership (TIP) is a crucial element for both the survival and the growth of the SO. "When properly utilized, these strategic alliances can provide numerous advantages beyond operational efficiencies and effectiveness" (Kaasalainen et al., 2002, p. 209).

Given these assumptions, we focused on SO with and without a traditional industrial partner and with and without a university ownership. We investigated the extent to which TIPs contribute to the economic success of SO by comparing the performance of SO with and without TIPs (SOwithTIP and SOwithoutTIP). We developed an empirical analysis arising from an original extended database created through the use of a questionnaire with Italian SO characteristics (e.g. history of creation, motivation, capital structure, location) and balance sheets. Our analysis reveals an inspiring and provocative finding: no significant differences exist between SO development and performance as long as they are embedded or not in TIPs. Such finding might partly be explained by the cultural differences and independence attitude of SO (Shane, 2004; O'Shea et al., 2005; van Gelderen et al., 2005; D’Este, Perkmann, 2011). But the latter could hardly support such an unexpected finding compared to the existing literature. Rather, these results call for a reevaluation of the role of "traditional" industrial alliances for particular firms like SO. The reasons for which the development of SO displays similar figures with or without a traditional industrial partner lead to new explanations. In other words, a new vision of partnerships and innovative forms of contract need to be conceived in order to support a process involving research-based firms, with specific characteristics and needs, and where partners emerge usually ex-post. We suggest that specific industrial partnerships may be conceived not in the traditional sense, but rather in the form of a set of industrial relations between SO. Such a strategy could therefore provide alternative assets and resources for development and performance, establishing an economic community involving many companies working together to gain comparative advantages as a result of their symbiotic relationships (Moore, 1993, 1996, 2006; Iansiti, Levien, 2004). This constitutes a virtual industrial cluster. Consequently, as suggested by Steiner $(2002 ; 2004)$ in his reflections on the adoption of new technologies and cluster development, we argue that strategic partnerships of actual SO cannot be merely apprehended through the traditional perspective of relations with some identified industrial partners, but they must additionally be conceived through the structure and embeddedness in their business ecosystem. The concept of a business ecosystem has been developed in recent literature based on complexity and evolutionary economics and has been applied specifically within the digital field (Coralloet al., 2007). It draws an analogy between the biological ecosystem and a population of organisations. Competition, cooperation, and evolution are observable not only in nature but also in socio-economic systems (Peltoniemi, 
2005). The growing interest of the concept is demonstrated by Moore (2006, p. 31): he recently argued that "markets, hierarchies and ecosystems are the three pillars of modern business thinking".

In order to analyse the characteristics of TIPs and their impact on SO performance, it sounded relevant to conduct a case-study of SO dynamics, examining hindrances and gaps in a specific country sharing similar institutional environment, geographical structuring and university framework. Due to recent initiatives - a growing interest in the SO phenomenon - and the increasing number of established SO, Italy emerged as a suitable case-study for such an investigation. First, Italian industrial districts (Garofoli, 1992, 2002; Becattini et al., 2003; Bertolini, Giovannetti, 2006; Hervàs-Oliver, Albors-Garrigòs, 2007; Parrilli, 2009; Camuffo, Grandinetti, 2011) and a fertile and industrialised context in the North (Nosella, Grimaldi, 2009) make Italy an interesting case in terms of variety of existing SO and potential distinctiveness. Additionally, several initiatives have been carried out in recent years in order to improve conditions that promote the establishment of SO (Mustar, Wright, 2010; Iacobucci et al., 2011). These initiatives include (i) the creation of SO regulations within many Italian universities following the Legislative Decree n. 297/1999 (Co-author ${ }^{3}$, 2009), (ii) the creation of Technology Transfer Offices (TTOs) and Industrial Liaison Offices (ILOs) following the law 262/2004 (Nosella, Grimaldi, 2009), and (iii) increased attention devoted to science park and incubator structures. TTOs, ILOs and incubators are important for promoting the transfer of expertise and resources from the research world to the market one, even if available funds are limited (Iacobucci et al., 2011). Italy hosts several universities ${ }^{4}$, a dense network of industrial firms, and a high level of scientific research (Breschi et al., 2008; Geuna, Rossi, 2011; Pezzoni et al., 2012). Furthermore, Italy has historically been characterised by a strong regional and innovation divide that is among the sharpest in the European Union (Iammarino et al., 2009) and may therefore support interesting comparisons between its regions.

The paper is structured as follows. Section 1 provides the theoretical background, including an overview of the SO phenomenon and a survey on the importance of a partner for SMEs: differences between traditional types of partnership and new types of industrial partnership in the form of business ecosystems are highlighted. Section 2 presents the methodology and the empirical analysis, in which we support our results with both a questionnaire and a regression model studying the existence of and comparisons between SOwithTIP and SOwithoutTIP. Finally, section 3 discusses the inspiring nature of our results and proposes explanations of such unexpected findings apparently contradictory with the current literature. Section 4 highlights our conclusions.

\section{Theoretical framework}

Establishing industrial partnerships and/or calling upon external managers has been frequently proposed as a solution to bridge the gap between cultures, competencies, and attitudes of researchers and businesspeople: cf. Franklin et al., 2001; Lockett et al., 2003;Wright et al., 2004, 2007; Mustar et al., 2006. Despite strong academic backgrounds, SO face difficulties that are thought to arise from a lack of managerial

\footnotetext{
${ }^{3}$ Author and co-author's references have been cancelled in the reference list in order to keep it anonymous.

4“Italy and France historically are considered the birth places of the university institution", Daraio et al. (2011), p. 154.
} 
and business competencies (Shane, 2004; Wright et al., 2007, 2004; Mustar et al., 2008; Harrison, Leitch, 2010; Clarysse et al., 2011; Iacobucci et al., 2011). For this reason, a large part of the literature is focused on the structuring and distribution of knowledge resources in the SO organization and environment. This context involves also the role played by TIPs and highlights the potential role that could instead be played by new types of partnerships in the form of (digital) business ecosystems (BES).

\subsection{The research spin-off phenomenon in the literature}

Notwithstanding the great attention in the literature (Lockett et al., 2005; Mustar et al., 2006; Mustar et al., 2008), a precise and well-accepted definition of SO does not currently exist (Iacobucci et al., 2011). This has been recently confirmed by Muller (2010, p. 189): “when examining academic spin-offs, one comes across a wide variety of spin-off definitions throughout the literature" and by Bathelt et al. (2010, p. 522): "there is not a widely accepted definition". The heterogeneity in SO definitions highlights the inherent complexity of the SO phenomenon. Yet, these peculiar firms share some common attributes that may help to provide an extensive framework for understanding their evolution.

SO are broadly defined in the literature to be new firms created to develop knowledge, technology, and university research results for commercial use (Clarysse et al., 2002; Wright et al., 2004). According to Pirnay et al. (2003, p. 356) "spin-off" is a fuzzy and general concept that covers a wide variety of phenomena among which the USO [university spin-off] represents only one specific type. (...) In particular, a USO refers to a spin-off firm that is created from a particular type of "parent organization", namely a university. Anyway, there have been many attempts to explicitly define a USO".

The following are among the most widely known and cited definitions and peculiarities of SO.

Shane (2004, p. 4) "defines a university spin-off as a new company founded to exploit a piece of intellectual property created in an academic institution (...). Thus university spin-offs are a subset of all start-up companies created by the students and employees of academic institutions".

In recent years, studies on SO have adopted a narrower definition because of the difficulties involved in trying to identify the number of SO. For instance, Wright et al. (2007, p. 4) define university SO as "new ventures that are dependent upon licensing or assignment of an institution's IP for initiation". Nonetheless, given the reality of some universities in which IP is not necessarily owned by the university, and given the existence of many companies without formal, codified knowledge embodied in patents, the authors include in their definition "start-ups by faculty based in universities which do not involve formal assignment of the institution's IP but which may draw on the individual's own IP or knowledge" (Wright et al., 2007, p. 4). They exclude only those companies established by graduates.

In a recent analysis on Italian SO, Iacobucci et al., (2011, p. 517) provided the following alternative definition: "academic spin-off means a company set up for the industrial development and economic exploitation of the results of research conducted in the PRI [public research institutions], according to the abovementioned regulations". In comparison, Harrison and Leitch (2010, p. 1250) defined "formal" SO to be companies based on the exploitation of the intellectual property of a higher education institution, with and 
without an equity involvement of this institution. Nonetheless, they also underlined the sharp increase in the number of companies initiated by UK graduates.

Furthermore, in addition to the varied definitions found in the literature, the existence of SO and the collection of reliable official data on this phenomenon are both affected by institutional differences arising from, for example, the US Bayh Dole Act or the professor's privilege in Sweden (Chapman et al., 2011; Farnstrand Damsgaard, Thursby, 2012). Drawing upon the resource-based view of the firm (Barney, 1991; Barney et al., 2001), Druilhe and Garnsey (2004) identified the essence of entrepreneurial activity to be the way in which academic entrepreneurs identify, select, and finally match up viable productive opportunities and resources.

In summary, concrete difficulties prevent the determination of applicable criteria for identifying a firm as a SO. At the core of this problem is the concept of "scientific knowledge", even if no clear consensus exists in the literature regarding its definition (Niedergassel, Leker, 2011). As a consequence, we should aim to determine whether knowledge has been transferred from the parent institute to the firm, and if so, to examine the nature of this transfer. In this paper, we therefore define SO to be the set of firms established by current or former university/research centre members (e.g. professors, researchers, technical and administrative staff, and $\mathrm{PhD}$ candidates) for the purpose of exploiting research results, regardless of whether the firm holds a university share or patent.

\subsection{The importance of a traditional industrial partner for SMEs and new emerging perspectives for research spin-offs}

In high technology like in more traditional firms, the literature highlights benefits and advantages of alliance arrangements in particular for SMEs. The formation of strategic alliances is considered to be more and more pivotal for firms. It has been attributed to responses to rapid environmental changes, such as intensification of competition, acceleration of technology advancements, and enlargement of required investment and globalisation of the markets (Yasuda, 2005). According to Mohr and Spekman (1994, p. 135), "partnerships are defined as purposive strategic relationships between independent firms who share compatible goals, strive for mutual benefit, and acknowledge a high level of mutual interdependence". The formation of these partnerships aims at achieving goals that a firm alone could find difficult to achieve and at gaining competitive advantage in the marketplace. More than ten years ago Miles et al. (1999, p. 20) argued that "evidence suggests that [strategic alliances] are a reasonable choice" and Ingham and Mothe (1998, p. 249) affirmed that "alliances are increasingly becoming a necessity for firms involved in technology". "Coping with environmental conditions is particularly hard for small and medium sized enterprises that are operating in technology intensive industries" (Kaasalainen et al., 2002, p. 210). The most influential explanations for alliances are the resource-based theory (Barney, 1991; Barney et al., 2001) and the transaction-cost theory (Yasuda, 2005; de Faria et al., 2010): the former argues that alliances arise when firms need additional resources that cannot be purchased via market transactions, while the latter argues that firms form alliances if they can use them to reduce their transaction costs. The empirical analysis undertaken by Yasuda (2005) recognized that the primary motivations for alliances can be categorized as access to the 
partner's resources, shortening of the time to market or reduction of the cost, and the resource-based theory prevailed over the transaction-cost theory to explain strategic alliances in high-technology industries.

The literature highlights potential advantages of alliances, but the overall impact of alliance use on firm performance is not well-defined. SMEs, in particular, call for technological partnerships more than business and managerial ones. A partner could be useful not only for filling the business knowledge gap, but also for market goals: more than twenty years ago Hamel et al. (1989, p. 133) argued that "it takes so much money to develop new products and to penetrate new markets that few companies can go it alone in every situation". Nevertheless, even if the formation of alliances between firms is seen as a common way for achieving and maintaining competitive advantage, most part of such partnerships do not succeed (Chen, 2004; de Man, Duysters, 2005; Lokshin et al., 2011). Yet, partnering relationships are accompanied by increased complexity, loss of autonomy and information asymmetry. Mohr and Spekman (1994) built and tested a model of partnership success addressing its main characteristics. Factors associated with partnership success are partnership attributes of commitment, coordination and trust, communication quality and participation, the importance of joint problem solving as a conflict resolution technique. Revilla et al. (2005) focused on communication, collaboration and integration as required elements for maximizing the synergy.

These factors are significant but difficult to detect when we talk about SO characterized by a strong attitude at individualism (Shane, 2004; O'Shea et al., 2005), influenced by universities' non-commercial cultures (Wright et al., 2004, 2007; Clarysse et al, 2011a) and considering that "academics and business people effectively speak different languages" (Wright et al., 2007, p. 189; Mustar et al, 2008, p. 76; Mustar, Wright, 2010, p. 52). In many cases these factors may result in tension and possible misunderstandings because of cultural differences (Samsom, Gurdon, 1993; Cyert, Goodman, 1997). In recent years Bjerregaard (2010) as well as Niedergassel and Leker (2011, p. 142-143) have argued "universities and companies have fundamentally different cultures and are perceived to have distinct social, cultural and economic roles...time horizons and the methods of validation and reward differ considerably...academic scientists perceive the short-term orientation of their industrial counterparts to be a major barrier for successful interaction". Speaking of alliance and partnership call for considering the role and condition of "trust" between partners (Sherwood, Covin, 2008; Bruneel et al., 2010; Niedergassel, Leker, 2011), because SO hold "tacit knowledge" (Shane, 2004; Clarysse et al., 2011). The transfer of this difficult-to-codify kind of knowledge can enable an opportunistic behaviour of the receiving firm (Dutta, Weiss, 1997). Knowledge transfer between partners is difficult: "differences in corporate culture, processes and knowledge base may impede a smooth transition of knowledge" (de Man, Duysters, 2005, p. 1379). This problem of information asymmetry and the liability of newness have been highlighted by Wright et al. (2004). The tacit component of transferred knowledge and successful relationships building between different organizations, are also linked to the broad set of skills known as absorptive capacity. Zahra and George (2002) stressed the importance of absorptive capacity as a dynamic capability relating to knowledge creation and use. This dynamic capability influences and enhances a firm's ability to gain and sustain a competitive advantage, thereby improving economic performance. In other words, this set of organizational routines and processes for acquiring, 
assimilating, transforming and using knowledge in order to produce a dynamic organizational capability (Zahra, George, 2002), is a relevant factor for the capacity of firms to absorb different types of knowledge and to collaborate effectively with non-academic partners.

Lastly, "industrial partners may have agendas that are not compatible with those of the entrepreneur, may have shorter term horizons that are not compatible with the development of the technology, may have considerably greater bargaining power over the distribution of gains at later stages in the process and may also place pressures on university to cede IP to them on disadvantageous terms" (Wright et al., 2004, p. 308; 2007, p. 157). Considering that alliances are a reasonable choice for SMEs on the one hand, and a majority of such partnerships does not succeed on the other hand, Niedergassel and Leker (2011, p. 148) investigated $\mathrm{R} \& \mathrm{D}$ cooperation projects and concluded that "industry might consider new organizational forms of cooperative $R \& D$ projects to achieve higher levels of closeness with academic partners. For instance, in the chemical industry many firms recently established separate organizational units designed to enhance cooperative activities with external partners". This new approach enables the different partners to work in close physical proximity for longer periods of time and gives an opportunity for a shared cultural space that lays the foundation for high-quality relationships fostering tacit knowledge sharing. In the case of SO, a solution suggested in the literature is the attraction of surrogate entrepreneurs or external managers in the founding team of the company in order to compensate for the lack of entrepreneurial culture (Franklin et al., 2001; Lockett et al., 2003; Wright et al., 2004, 2007; Mustar et al., 2006). According to Shane (2004, p. 248), SO perform better if their founding team gathers people with industry experience and business knowledge. But "this alone is not enough... a successful university spin-off also needs inventor involvement". Furthermore, this solution is not without drawbacks: it can be difficult to attract the best surrogate entrepreneur because of remuneration required and/or lack of suitable candidates (Franklin et al., 2001; Wright et al., 2004). As an alternative, Wright et al. (2004, p. 301) suggested the establishment of a joint venture spin-off (JVSO), where the industrial partner provides or substitutes surrogate entrepreneurs. But they also highlighted that the strong academic backing and know-how "brings scientific credibility to the venture which the industrial partner cannot otherwise attain". In short, according to Miles et al.(1999, p. 2021), small technology-based firms "are ideal candidates for alliance arrangements", because they have innovative ideas and products as well as weak resources and experience, but it is also underlined that "alliances alone are no guarantee of successful performance". Furthermore, "alliances are not a cure-all for such firms. If the firm does not strive to develop itself as a viable independent entity, forging strategic alliances, no matter how successful, may not turn out to benefit the firm fully" (Miles et al., 1999, p. 28). Nevertheless, strategic alliances are not a remedy to all companies' problems (de Man, Duysters, 2005) and Wright et al. (2004) acknowledge that collaboration is not a panacea for firms with limited resources like SO ones. Miles et al. (1999) found no difference in performance between firms involved in alliances and those not involved. One of the main problems is given by the recognition of alliance as a potential business opportunity: founders of new technology-based firms have a strong "independence" attitude and may develop organizational egocentricity (Venkataraman et al., 1990). Our empirical results (cf. infra) are in line 
with this finding and they are strengthened by the singularity of the focus on particular firms as SO. To date, there are no other deep studies specifically focused on the issue of TIPs with SO. Therefore, the results of our investigation highlight that the specific case of SO calls for new ways of considering the role of TIPs for the development of the company. Actually, retaining the crucial role of shared knowledge in economic development, several papers suggested, in particular, that firms should go ahead elaborating over one to one industrial partnerships in order to embed themselves in more global Business Ecosystems (BES) either they are physical or digital.We specifically assume that the concept of BES is a suitable and effective complement to the establishment of TIPs and the formation of a classical cluster in a given geographical area (Porter, 2000; Steiner, 2004). It is a pivotal tool in order to make clarity in the complex and confused world of SO. BES could have important consequences for the design of industrial policies and public support. Thinking about SO as BES could be a first step in order to try to implement policies at country level and not only at the single university level and to shed some light on a complex and confused phenomenon like SO, where no official statistics and no agreed definition exist.

In order to draw the lines of our discussion and understand the effective meaning of the results of our empirical analysis, Table 1 provides an enlightenment of the main features identifiable in a TIP as well as in new types of partnerships, meaning physical and/or digital BES. Actually, business ecosystem is an emerging concept analogized from biology (Hannon, 1997). According to Peltoniemi and Vuori (2004) a business ecosystem is a dynamic structure which consists of an interconnected population of organizations. These organizations can be small firms, large corporations, universities, research centres, public sector organizations or any other actor which may influence the system. A business ecosystem develops itself through self-organization, emergence and co-evolution; competition and cooperation are both present (Corallo et al., 2007). Moore (1996) argues that in each ecosystem there is a large dominant actor, the "keystone species", but it is not a powerful leader, because control is decentralised. In the specific case of SO, universities, science parks and incubators should play an integration role in connecting all the companies in a given industrial sector to a platform that aims to become a business ecosystem. In fact, a business ecosystem is not based on the geographical propinquity that is a feature of clusters ${ }^{5}$. It rather relies on competition and cooperation, interconnectedness and shared fate in a changing environment. A central importance is also given by interdependency and integration: business's performance is dependent on the firm influencing assets outside its direct control and BES allow firms to create value that no single firm could create alone. A business ecosystem is a dynamic structure taking place as evolutionary mutual changes of organizations that interact and thus have an effect on one another. The symbiosis of a business ecosystem shares the fate of the network as a whole, regardless of the member's apparent strength, just as individual species in a biological ecosystem (Iansiti, Levien, 2004; Corallo et al., 2007).

\footnotetext{
${ }^{5}$ For a comparison of key features of cluster, value network and business ecosystem, see Peltoniemi (2005).
} 
Table 1: TIPS vs BES in the SO perspective

\begin{tabular}{|c|c|c|}
\hline & Traditional Industrial Partnerships (TIPs) & $\begin{array}{c}\text { Non-traditional partnerships: (Digital) Business } \\
\text { Ecosystems (BES) }\end{array}$ \\
\hline \multirow{10}{*}{$\begin{array}{l}\text { Main } \\
\text { features }\end{array}$} & $\begin{array}{l}\text { One to one relationships, closeness of partners, } \\
\text { geographically limited }\end{array}$ & $\begin{array}{l}\text { Collective relationships; (e)-network of alliances; } \\
\text { sharing of common knowledge background among } \\
\text { several actors, not geographically limited: Digital } \\
\text { BES, Nachira, (2002), Nachira et el. (2007) }\end{array}$ \\
\hline & $\begin{array}{l}\text { Long range cooperative associations on } \\
\text { common projects (of specific interest), } \\
\text { Hagedoorn et al. }(2000) \text {; Yasuda (2005) }\end{array}$ & $\begin{array}{l}\text { Ad hoc and varied associations on needs (of general } \\
\text { interest) }\end{array}$ \\
\hline & $\begin{array}{l}\text { Inherent tension between cooperation and } \\
\text { competition }\end{array}$ & $\begin{array}{l}\text { Independence, cooperation and mutualistic co- } \\
\text { evolution, } \operatorname{Li}(2009)\end{array}$ \\
\hline & Ex-ante identified partners & $\begin{array}{l}\text { Dynamic structure: partners emerge during the } \\
\text { process }\end{array}$ \\
\hline & $\begin{array}{l}\text { Substitution logic: separate and well defined } \\
\text { role of every actor }\end{array}$ & $\begin{array}{l}\text { Complementary logic: mutual interdependence and } \\
\text { scientific expertise }\end{array}$ \\
\hline & Clear value chain skills & $\begin{array}{l}\text { Disruptive skills, tacit and codified knowledge, Shane } \\
\text { (2004); Clarysse et al. (2011) }\end{array}$ \\
\hline & Traditional contracts; formal relationships & $\begin{array}{l}\text { Innovative contract relationships; self-organization, } \\
\text { emergence and co-evolution, Corallo et al. (2007); } \\
\text { close, informal relationships }\end{array}$ \\
\hline & $\begin{array}{l}\text { Transaction-cost theory, Yasuda (2005); de } \\
\text { Faria et al. (2010); resource-based view, } \\
\text { Barney (1991); Barney et al. }(2001)\end{array}$ & Bundle of similar characteristics \\
\hline & $\begin{array}{l}\text { Risk of failure because of opportunistic } \\
\text { behaviour, information asymmetry, increased } \\
\text { complexity, loss of autonomy, Chen (2004); } \\
\text { Wright et al. (2004); de Man, Duysters (2005); } \\
\text { Lokshin et al. (2011) }\end{array}$ & $\begin{array}{l}\text { Competition and cooperation, interconnectedness and } \\
\text { shared fate, interdependency and integration, Moore } \\
\text { (1993) }\end{array}$ \\
\hline & $\begin{array}{l}\text { Communication problems because of cultural } \\
\text { differences and SO independence attitude, } \\
\text { Shane (2004); O'Shea et al. (2005); van } \\
\text { Gelderen et al. (2005); D'Este, Perkmann } \\
\text { (2011) }\end{array}$ & $\begin{array}{l}\text { Shared cultural space: same research origin, same } \\
\text { language, better communication, complementary } \\
\text { capabilities, Niedergassel and Leker (2011); } \\
\text { Bjerregaard (2010) }\end{array}$ \\
\hline $\begin{array}{l}\text { Learning } \\
\text { process }\end{array}$ & $\begin{array}{l}\text { Reciprocal exchange (i.e. supply of } \\
\text { information/expertise vs supply of capital); } \\
\text { development of trust in an unfamiliar context; } \\
\text { absorptive capacity, Zahra, George (2002) }\end{array}$ & $\begin{array}{l}\text { Collective, informal and interpersonal relations in a } \\
\text { familiar context (i.e. reciprocal scientific and } \\
\text { technical learning for common advancement), cross- } \\
\text { fertilization, platform building }\end{array}$ \\
\hline \multirow{4}{*}{$\begin{array}{l}\text { Public policy } \\
\text { implications }\end{array}$} & Industrial support to firms & $\begin{array}{l}\text { Virtual cluster structuring; exchange of advice; } \\
\text { creation of a set of industrial relations between SO; } \\
\text { symbiotic relationships, Moore (1993, 1996, 2006); } \\
\text { Iansiti, Levien (2004) }\end{array}$ \\
\hline & Autonomous identity of every partner & $\begin{array}{l}\text { Creation of a stimulating industrial environment, a } \\
\text { group identity and collective responsibility }\end{array}$ \\
\hline & Sector specific policies & Country level policies instead of university level ones \\
\hline & $\begin{array}{l}\text { Governance mode: the strongest partner leads } \\
\text { the partnership process }\end{array}$ & $\begin{array}{l}\text { Governance mode: leadership of intermediary } \\
\text { institutions: universities, science parks and incubators }\end{array}$ \\
\hline
\end{tabular}




\section{Methodology and results}

Given the strong desire for independence of SO on the one hand (O'Shea et al., 2005; van Gelderenet al., 2005; D'Este, Perkmann, 2011) and the lack of managerial and business competencies on the other hand (Shane, 2004; Wright et al., 2007, 2004; Mustar et al., 2008; Clarysse et al., 2011), our goal was first of all to verify in which extent SO were rooted or not in the set of TIPs. Consequently, first of all we aimed at investigating the existence and the potential importance of a TIP for this particular kind of firm. Secondly, on the base of the results of the empirical analysis, we discussed and emphasized the role of "non"-traditional partnerships in the form of BES. SO founders are scientists and not managers, therefore differences might be expected in the way they run their company and in their performance, according they call or not for complementary competencies and assets through TIP. In order to investigate similarities between a SOwithTIP and a SOwithoutTIP, we built a specific questionnaire on these issues and we created a related database of the content of the questionnaires received (i.e. a specific section of the questionnaire investigated the main reasons for partnership creation and how it was implemented, or why the company had not looked for a partnership till then). It provided the basis for statistical comparative description and regression model. In a preliminary and exploratory phase, some face-to-face interviews enabled us to settle the specific industrial context of SO and, consequently, to build the questionnaire. A general investigation, not centred only on the existence of an industrial partnership, was useful as a means of overcoming possible wariness of the respondent on the reasons of the enquiry and enabled us to check the accuracy and coherence in the answers to the various sections. In addition, the data have been enriched by the provision of formal information collected from balance sheets.

As expected, the results of the empirical analysis revealed similarities in some aspects and differences in others, even if the differences are subtle while the similarities are very evident. This finding will lead our following discussion about the potential role of BES, with suggestions for improvement of SO industrial policies.

\subsection{The empirical analysis: methodological insights}

The main concrete problem of the empirical analysis has been to identify the actual number and structure of SO founded in Italy. In fact, no official, complete and updated list of SO at the regional or national level does exist (Iacobucci et al., 2011). A similar problem has been recently encountered by Chapman et al. (2011) in an analysis focused on university-related companies in London: UK data collection on these companies has been formalized in recent years, but without the provision of significant information. Thus, the first step was to build such a database, investigating ILO, TTO and university websites to identify and collect the list of SO they point out, then verifying the completeness and updating of this list. A specific problem was due to the fact that each university takes care only of their "own" SO: the ones they participated to. Considering that the usual definition of SO includes, in general, companies built out of R\&D and is not only restricted to the ones participated by a university, we completed our first list with the Italian science park and incubator tenants list. Since science parks and incubators do not make any difference between SO and start-ups, we set up direct contacts (telephone and e-mail) with university staff as well as science park 
and incubator personnel. It gave us the possibility to filter the first list excluding firms not linked to the academic world.

Thus, we could identify $419 \mathrm{SO}^{6}$ constituting the SO Italian arena. Among them, $25 \mathrm{SO}$ had the positive approval of the university at the time of the survey, but they had not yet been established. In conclusion, we were able to contact 394 firms. Face-to-face interviews were carried out between September and October 2007 in some selected case-studies and a questionnaire was sent to each of the 394 Italian $\mathrm{SO}^{7}$. The response rate was 39.5\%: 155 SO accepted to answer to the questionnaire. Lack of time and privacy were the most predominant reasons for not participating in the questionnaire investigation: these motivations seem sound considering the inflationary rate of questionnaires received by SO in recent years (Gupte, 2007). Nevertheless, according to the sample size, to the geographical distribution of the universe and of the sample $^{8}$ and to the response rate in general achieved ${ }^{9}$, we can reasonably consider this sample as representative.

The limits of a standard questionnaire were supplemented through further information obtained with Internet searching. Additionally, some interviews were undertaken before drawing up the questionnaire as a crucial tool in order to understand the general context and check the main aspects of deep examination.

As we already explained, the final questionnaire was divided in several sections. The following analysis presents, on the one hand, the statistical description of the role played by TIPs according to the questionnaire answers. It portrays the main characteristics of SO and it provides inspiring comparisons regarding some main dimensions of these firms (e.g. history of creation, motivations, capital structure, location). On the other hand, we built a regression model in order to weight the influence of the presence or the absence of a TIP on added value of a SO. An objective assessment based on data gathered through Aida data bank $^{10}$ has been used in order to confirm and deepen the questionnaire results. The aim of the comparison was to highlight whether there have been any differences in added value between SOwithTIP and SOwithoutTIP in the year 2007 through the use of data taken from balance sheets. We decided to limit the analysis on the year 2007 to be in tune with our investigation period on the universe of Italian SO (January-June 2008). Given the difficulty of obtaining data on Italian SO, we were able to identify 98 SO $(63.5 \%)$ starting from the original sample of 155 who originally answered our questionnaire. Among the 57 missing firms: 9 companies established in 2008 and 22 created in 2007 had not yet deposited the balance sheet at this time; the remaining were not available on Aida since the specific and limited form of

\footnotetext{
${ }^{6}$ This list is updated at June 2008 (year of the empirical investigation through a questionnaire).

${ }^{7}$ The questionnaire was sent by e-mail to SO between January and June 2008 with information about the purpose and details of the survey. An e-mail reminder was sent to firms that did not reply to the first e-mail within a month.

${ }^{8}$ The distribution by Regions of the 155 questionnaires revealed that $58 \%$ was from the North, $23 \%$ from the Centre and $19 \%$ from the South and Islands, while the Italian distribution of the 419 SO showed $54 \%$ from the North, $25 \%$ from the Centre and $21 \%$ from the South and Islands.

${ }^{9}$ Sheehan (2001) finds response rates to oscillate between $21.6 \%$ and $36 \%$ and Jobber and Saunders (1993) indicate that the rate of response in business-oriented studies is more sensitive than consumers' ones to characteristics as the number of questions, the length of the survey, etc. [cited in Squicciarini, 2008, p. 50].

${ }^{10}$ AIDA is a databank that provides company accounts, ratios, activities for 950,000 Italian companies.
} 
partnerships (not capital supported) was not taken into account in the databank (for $5 \mathrm{SO}$ ), or because of their low level of capital (for $21 \mathrm{SO}$ ).

\subsection{Results: the - unexpected - limited role of TIPs for $\mathrm{SO}$}

The overall sample was divided in two groups in order to compare SOwithTIP and SOwithoutTIP companies. We shall firstly present the main findings of descriptive statistics and then our regression model.

The first - and somehow main - results confirm that SO are not used to collaborate with TIPs and that in any case TIPs did not matter much for SO' performance. Our analysis revealed that $56 \mathrm{SO}(36 \%)$ out of 155 have an alliance, while 99 (64\%) are without alliance companies. Surprisingly, findings showed few conclusive differences between the two groups. Furthermore, at best the evidence suggests that the characteristic of being a SOwithTIP or not had no influence on the level of added value in the year 2007. There was no different performance between SOwithTIP and SOwithoutTIP in 2007 in terms of added value, as showed by the regression model that is highly significant (see Model 1 table in Appendix). These findings suggest that SO performance is not strictly in relation with TIPs: this calls, then, to a broader perspective, putting at stake pivotal factors such as age, resources, motivations, location issues, industrial context, university and science park-incubator involvement, and presence of patents.

Consequently, considering the characteristics of $\mathrm{SO}$, the results are more specifically presented in the following order. Since the literature suggests the importance of organisational learning and the specificities of SO, we firstly considered the age impact looking at the history of creation: a slight difference in age has been observed, thus confirming the reliability of the comparison between SOwithTIP and SOwithoutTIP. Then, we verified the influence of the institutional form of the society on the propensity to develop TIPs (unexpectedly most SOwithTIP as well as SOwithoutTIP are limited liability companies ${ }^{11}$ ) and the motivations that led SOwithTIP to look for a traditional industrial partner. Surprisingly, the "lack of managerial and financial competencies" is not one of the first choices: this finding suggests that, notwithstanding the attention provided by the literature, a TIP is not considered by SO themselves as the best solution to the knowledge gap. It is also worth noting the autonomy propensity given by the choice of selftraining as main solution chosen for filling the knowledge gap as well as the significance of the perception of no lack of managerial competence. Subsequently, given the importance of the contribution to capital, accordingly we analysed the differences in capital structure between SOwithTIP and SOwithoutTIP: as expected, differences in capital structure exist, but they are not very marked. Afterwards, given the fact that "the spatial location of firms is particularly important when considering a country characterised by a considerable regional divide as Italy" (Iammarino et al., 2009, p. 99)we examined the role of location. While industrial intensity may be different according to the Italian regions, our results demonstrated the absence of significant differences among the North, the Centre and the South of Italy; we verified a possible difference in the interest of the university and the science park-incubator as well as the presence of a patent. Again, similarity instead of difference emerged. This was confirmed by the absence of specificities in the sector and

11Namely s.r.1., in Italian legal terms. 
product or service orientation. Finally, we investigated differences in the performance: in line with the questionnaire results, an absence of marked impact emerged.

Given these assumptions, the following description of the results of our investigation clearly demonstrates that TIPs play a limited role for SO growth and development: they provide capital and competencies, but their contributions are not translated into a superior performance and/or differences in company legal form, location, university and science park-incubator interest, presence of patents, industrial sector and productservice activity. This finding drives our subsequent discussion about the complementary role that could be played by the structuring of BES.

\subsubsection{Similar age effects}

According to the literature (Shane, 2004; Lockett et al., 2005; Wright et al., 2007), the history of creation shows off a significant growth of Italian SO in recent years. More specifically, table 2 highlights an increased development of SOwithTIP since 2005, while SOwithoutTIP were increasing yet since 2003.

Table 2: Year of creation

\begin{tabular}{ccccc}
\hline Year & SOwithTIP & $\%$ & SOwithoutTIP & $\%$ \\
\hline 1995 & 0 & 0 & 1 & 1.01 \\
1996 & 1 & 1.79 & 0 & 0 \\
1997 & 0 & 0 & 3 & 3.03 \\
1999 & 1 & 1.79 & 1 & 1.01 \\
2000 & 4 & 7.14 & 3 & 3.03 \\
2001 & 1 & 1.79 & 1 & 1.01 \\
2002 & 3 & 5.36 & 3 & 3.03 \\
2003 & 2 & 3.57 & 10 & 10.10 \\
2004 & 5 & 8.93 & 12 & 12.12 \\
2005 & 10 & 17.86 & 13 & 13.13 \\
2006 & 14 & 25.00 & 17 & 17.17 \\
2007 & 13 & 23.21 & 26 & 26.26 \\
2008 & 1 & 1.79 & 8 & 8.08 \\
No answer & 1 & 1.79 & 1 & 1.01 \\
Total & 56 & 100.00 & 99 & 100.00 \\
\hline
\end{tabular}

Accordingly, in the regression model the average age of a SOwithTIP was 2.5 years while the average age of a SOwithoutTIP was 2.9 years. Results showed a weak significant coefficient $(\mathrm{P}<0.10)$ relating to the number of years on the market: every year older on the market, SO had also a higher level of added value of Euros 27,681 in average (see Appendix).

The slight difference in age can be explained by the success of the concept and some fashion effects while the number of available industrial partners did not grow in the same perspective. Asymmetric information (Akerlof, 1970), self-governance tendency on the part of SO and a general independence attitude (Shane, 2004; O'Shea et al., 2005; van Gelderen et al., 2005; D’Este, Perkmann, 2011) are key obstacles. Yet, the absence of marked differences in the history of creation provides interesting data to compare the situation and the success of SOwithTIP and SOwithoutTIP. 


\subsubsection{Similar legal patternbut different motivations}

First of all, we verified the formal legal structure of the companies. Surprisingly, no significant differences emerged. In line with the results of the survey undertaken by Iacobucci et al. (2011), the prevalent form of society for both the groups of SO is limited liability company - s.r.1. - (more than 90\%); two or three firms are joint-stock companies - S.p.A. - and two or three are limited partnerships. Furthermore, the variable "company" was not a statistically significant variable in the regression model (see Appendix).

First reasons for creation of the firm are the same: use research results (35\% as first choice) and move from idea to market (more than 20\%). Motivations for the presence or absence of a TIP are, of course, different: SOwithoutTIP have affirmed that the main reason of partnership absence is linked to their young age. The reasons for the choice of an industrial partner for SOwithTIP are linked to the possibility of increasing the number of customers and of commerce as well as to similar interests and activities, while the lack of managerial and financial competencies has a minor importance (table 3 ).

Table 3: Reasons for the choice of an industrial partner

\begin{tabular}{lcccr}
\hline Possible answers & First choice & \multicolumn{2}{c}{ Second choice } \\
\hline & SO & $\%$ & SO & $\%$ \\
More visibility and external prestige & 6 & $10.71 \%$ & 6 & $10.71 \%$ \\
More credibility towards clients & 1 & $1.79 \%$ & 5 & $8.93 \%$ \\
More clients and commerce & 19 & $33.93 \%$ & 5 & $8.93 \%$ \\
Move from national market to international market & 0 & $0.00 \%$ & 4 & $7.14 \%$ \\
Possibility of stock exchange quotations & 0 & $0.00 \%$ & 0 & $0.00 \%$ \\
More security and defence against competitors & 1 & $1.79 \%$ & 1 & $1.79 \%$ \\
Need of financial resources & 5 & $8.93 \%$ & 5 & $8.93 \%$ \\
Lack of managerial and financial competencies & 6 & $10.71 \%$ & 4 & $7.14 \%$ \\
Common interests and activities & 10 & $17.86 \%$ & 17 & $30.36 \%$ \\
Other & 5 & $8.93 \%$ & 5 & $8.93 \%$ \\
No answer & 3 & $5.36 \%$ & 4 & $7.14 \%$ \\
Total & 56 & $100.00 \%$ & 56 & $100.00 \%$ \\
\hline
\end{tabular}

It is therefore interesting to highlight the answers provided by SOwithTIP and SOwithoutTIP to the question about the solutions to lack of managerial competence (table 4).

Table 4: Solutions to lack of managerial competence

\begin{tabular}{lcccc}
\hline Possible answers & \multicolumn{2}{c}{ SOwithTIP } & \multicolumn{2}{c}{ SOwithoutTIP } \\
\hline & SO & $\%$ & SO & $\%$ \\
External manager & 7 & $12.50 \%$ & 14 & $14.14 \%$ \\
Aid from incubator & 6 & $10.71 \%$ & 23 & $23.23 \%$ \\
Self-training & 19 & $33.93 \%$ & 35 & $35.35 \%$ \\
Aid from industrial partner & 10 & $17.86 \%$ & 0 & $0.00 \%$ \\
No lacks & 11 & $19.64 \%$ & 22 & $22.22 \%$ \\
No answer & 3 & $5.36 \%$ & 5 & $5.05 \%$ \\
Total & 56 & $100.00 \%$ & 99 & $100.00 \%$ \\
\hline
\end{tabular}

Surprisingly, "self-training" is the first answer for SOwithTIP as well as for SOwithoutTIP, followed by "no lacks" and then by "aid from industrial partner" for SOwithTIP and "aid from incubator" and "no lacks" for SOwithoutTIP. Furthermore, "external manager" is not one of the first choices for both the samples of firms. This result confirms that aid from a traditional industrial partner and from an external 
manager is not considered by SO themselves as key solutions. Aid from incubator has more importance for SOwithoutTIP even if the percentage of hospitality in a science park-incubator is quite similar for SOwithTIP and SOwithoutTIP (see section 2.2.5). We can, therefore, assume that aid from incubator for SOwithoutTIP substitutes aid from industrial partner for SOwithTIP.

Looking more specifically at the partnership, it has been established with a contribution to capital (48.21\%) and to competencies (17.86\%); the presence of a patent has had no importance (table 5). The high percentage of contribution to capital is linked to the financing gap of newly established companies. Therefore, we can assume that a difference exists in the capital structure of SOwithTIP and SOwithoutTIP.

Table 5: Realisation of the partnership

\begin{tabular}{lcc}
\hline How the partnership has been established? & & \\
\hline & SO & $\%$ \\
Subdivision of competencies & 7 & $12.50 \%$ \\
Apport of capital & 27 & $48.21 \%$ \\
Apport of competencies & 10 & $17.86 \%$ \\
Apport of other subventions & 3 & $5.36 \%$ \\
Apport of a patent & 0 & $0.00 \%$ \\
Other & 3 & $5.36 \%$ \\
No answer & 6 & $10.71 \%$ \\
Total & 56 & $100.00 \%$ \\
\hline
\end{tabular}

\subsubsection{Differences in capital structure?}

As established from the results of table 6, differences exist, according the case, regarding the capital structure. The capital distribution has highlighted that the majority of SOwithTIP and SOwithoutTIP has a low capital, but $17.86 \%$ of SOwithTIP has a high capital compared to $8.08 \%$ of SOwithoutTIP (table 6). In particular, the number of SO with a high capital has doubled between the establishment of the firm and the year of investigation, while the number of firms with a low capital has diminished.

Table 6: Initial and present capital

\begin{tabular}{|c|c|c|c|c|c|c|c|c|}
\hline \multirow{3}{*}{ Capital (euro) } & \multicolumn{4}{|c|}{ SOwithTIP } & \multicolumn{4}{|c|}{ SOwithoutTIP } \\
\hline & \multicolumn{2}{|c|}{ Initial } & \multicolumn{2}{|c|}{ Year 2008} & \multicolumn{2}{|c|}{ Initial } & \multicolumn{2}{|c|}{ Year 2008} \\
\hline & SO & $\%$ & SO & $\%$ & SO & $\%$ & SO & $\%$ \\
\hline $\begin{array}{l}\text { Very low }(<10,000) \\
\text { Low (from } 10,000 \text { to }\end{array}$ & 0 & $0 \%$ & 0 & $0 \%$ & 5 & $5.05 \%$ & 2 & $2.02 \%$ \\
\hline $\begin{array}{l}20,000 \text { ) } \\
\text { Medium (from } 20,001 \text { to }\end{array}$ & 39 & $69.64 \%$ & 33 & $58.93 \%$ & 68 & $68.69 \%$ & 62 & $62.63 \%$ \\
\hline $\begin{array}{l}50,000) \\
\text { Medium-high (from }\end{array}$ & 8 & $14.29 \%$ & 8 & $14.29 \%$ & 11 & $11.11 \%$ & 16 & $16.16 \%$ \\
\hline 50,001 to 90,000$)$ & 3 & $5.36 \%$ & 3 & $5.36 \%$ & 9 & $9.09 \%$ & 8 & $8.08 \%$ \\
\hline High (> 90,000) & 5 & $8.93 \%$ & 10 & $17.86 \%$ & 4 & $4.04 \%$ & 8 & $8.08 \%$ \\
\hline No answer & 1 & $1.79 \%$ & 2 & $3.57 \%$ & 2 & $2.02 \%$ & 3 & $3.03 \%$ \\
\hline Total & 56 & $100.00 \%$ & 56 & $100.00 \%$ & 99 & $100.00 \%$ & 99 & $100.00 \%$ \\
\hline
\end{tabular}

Furthermore, $25 \%$ of SOwithTIP has registered an increase in capital compared to $14.14 \%$ of SOwithoutTIP.

If we compare the financial resources utilised by SO, our results show that personal capital has been utilised in percentage slightly higher by SOwithoutTIP, while regional, national and European funds have been utilised in percentage higher by SOwithTIP. A subtle difference is observable in the venture capital 
support (table 7), even if a venture capitalist is more willing to invest in SO where the team has business experience (Wright et al., 2007). And the limited number of SO supported by venture capitalists prevents us from investigating further the effective role of venture capital for these particular firms, even if BES could improve the interest and the participation of venture capitalists thanks to the inherent strength arising from such new types of partnerships.

Table 7: Financial resources

\begin{tabular}{lcccc}
\hline Possible choices & Yes (SOwithTIP) & $\%$ & Yes(SOwithoutTIP) & $\%$ \\
\hline 1-Personal and family capital & 45 & $80.36 \%$ & 86 & $86.87 \%$ \\
2-Bank loans & 6 & $10.71 \%$ & 8 & $8.08 \%$ \\
3-Regional, national, European grants; Start- & & & & \\
Cup $^{12}$; National Innovation Prize; MIP'13 & 33 & $58.93 \%$ & 41 & $41.41 \%$ \\
4-Venture Capital/Business Angels & 4 & $7.14 \%$ & 4 & $4.04 \%$ \\
5-Credit support & 1 & $1.79 \%$ & 1 & $1.01 \%$ \\
6-Other forms of support & 2 & $3.57 \%$ & 8 & $8.08 \%$ \\
\hline
\end{tabular}

\subsubsection{Location and industrial geographical context}

One may think that SO should more specifically be located near clusters and industrial areas. On the contrary, no specificity regarding the location and the industrial geographical context actually emerged. From this viewpoint, the case of Italy is particularly interesting because there is a wide tradition of industrial districts (Garofoli, 1992, 2002; Becattini et al., 2003; Camuffo, Grandinetti, 2011) and a strong geographical industrial characterization of regions, known as the Italian innovative and regional divide (Iammarino et al. 2009). Recently, Hussler et al. (2010, p. 512 and p. 514) investigated the development model of the Province of Milan in Lombardy Region (North of Italy): it is based on a network of small and micro companies integrated with a limited number of medium-large firms, "which make up the famous Italian industrial district" and "the Milan area is the most highly qualified scientific district in Italy". The delay in economic development in Southern regions compared to the Centre and the North of the country still persists (Bank of Italy, 2008; 2010).

Yet no significant difference emerged in the geographical distribution of SOwithTIP and SOwithoutTIP: the North of Italy is prevalent for both the samples (59\% for SOwithTIP and 58\% for SOwithoutTIP) with subtle differences for the Centre (30\% for SOwithTIP and 18\% for SOwithoutTIP) and the South (11\% for SOwithTIP and $24 \%$ for SOwithoutTIP). The questionnaire answers highlighted also a similar attitude at local/regional level for the market: $10.71 \%$ of SOwithTIP and $9.09 \%$ of SOwithoutTIP work on the local and regional market.

Furthermore, the regression model estimated using ordinary least squares (OLS) regression analysis did not highlight a significant coefficient for the variable "location" (see Appendix). We could then expect

\footnotetext{
${ }^{12}$ Start-Cup competition has the goal to foster and support the creation of high knowledge companies, to promote regional economic development and to stimulate the entrepreneurial orientation of researchers. The outcome is in form of awards, cash, training and advice services.

${ }^{13}$ MIP-Mettersi in Proprio (Start up your own business) is a support service to enterprise creation. It is made up of several integrated actions, with the aim of spreading a culture of entrepreneurship and of fostering the start-up and development of successful companies.
} 
that, if a difference does not exist in the location, it may be found in the parent institute interest (Link, Welsh, 2011).

\subsubsection{No difference in university and science park-incubator interest}

Surprisingly, the interest showed or not by the university towards the SO initiative, the hospitality or not in a science park or an incubator and the presence or not of a patent, did not show a significant difference between the two groups of firms. In fact, tables 8, 9and 10highlight a similar percentage for SOwithTIP and SOwithoutTIP.

Table 8: University interest

\begin{tabular}{lcccr}
\hline Possible choice & SOwithTIP & $\%$ & SOwithoutTIP & $\%$ \\
\hline University interest & 38 & $67.86 \%$ & 62 & $62.63 \%$ \\
Absence of university interest & 15 & $26.79 \%$ & 27 & $27.27 \%$ \\
No answer & 3 & $5.36 \%$ & 10 & $10.10 \%$ \\
Total & 56 & $100.00 \%$ & 99 & $100.00 \%$ \\
\hline
\end{tabular}

Table 9: Hospitality in an incubator or science park

\begin{tabular}{lcccr}
\hline Possible choice & SOwithTIP & $\%$ & SOwithoutTIP & $\%$ \\
\hline Hospitality in an incubator/science park & 23 & $41.07 \%$ & 42 & $42.42 \%$ \\
Absence of hospitality & 33 & $58.93 \%$ & 57 & $57.58 \%$ \\
Total & 56 & $100.00 \%$ & 99 & $100.00 \%$ \\
\hline
\end{tabular}

Table 10: Presence of a patent

\begin{tabular}{lcccr}
\hline Possible choice & SOwithTIP & $\%$ & SOwithoutTIP & $\%$ \\
\hline Presence of a patent & 14 & $25.00 \%$ & 26 & $26.26 \%$ \\
Absence of a patent & 42 & $75.00 \%$ & 72 & $72.73 \%$ \\
No answer & 0 & $0.00 \%$ & 1 & $1.01 \%$ \\
Total & 56 & $100.00 \%$ & 99 & $100.00 \%$ \\
\hline
\end{tabular}

\subsubsection{Similarity in industrial sectors and product or service activity}

Considering their offering, no specificity emerged among Italian SO, neither according to the industrial sector nor according to the structure of product or service activity. The industrial sector distribution highlights a prevalence of the ICT sector $(32 \%$ and $26 \%$ for SOwithTIP and SOwithoutTIP respectively); the engineering (25\% and $22 \%$ ) and the biopharmaceutical (16\% and $26 \%$ ) sectors follow. Again, the dummy variables for the industrial sectors were not statistically significant variables (see Appendix). Furthermore, we expected an influence of the industrial partner on the nature of the activity. Nonetheless, expected differences did not emerge. SOwithTIP affirmed to be product SO in percentage slightly higher than SOwithoutTIP (table 11).

Table 11: Product and service SO

\begin{tabular}{lcccc}
\hline & \multicolumn{2}{c}{ SOwithTIP } & \multicolumn{2}{c}{ SOwithoutTIP } \\
\hline \multirow{3}{*}{ SO } & & $\%$ & SO & $\%$ \\
Product & 20 & $35.71 \%$ & 31 & $31.31 \%$ \\
Service & 36 & $64.29 \%$ & 68 & $68.69 \%$ \\
Total & 56 & $100.00 \%$ & 99 & $100.00 \%$ \\
\hline
\end{tabular}




\subsubsection{The regression model ${ }^{14}$ : two specific findings regarding performance}

A regression model has been elaborated in order to corroborate and to strengthen the findings of the descriptive statistics. Our main argument was to focus on the influence of the presence or the absence of a TIP on added value of a SO. We considered only added value because of the difficulty in measuring the performance of new ventures and in obtaining reliable data on a particular kind of firm like the SO one.

The model has been specifically built on the following basis: in order to choose the balance sheets' variables to be included in the model we started from the main results of the questionnaire investigation ${ }^{15}$. The questionnaire data suggested us how to build the comparison between the two groups of SO. We used "added value" as dependent variable while the independent variables employed in the analysis were as follows: "flagspinoff" for SOwithTIP and SOwithoutTIP ${ }^{16}$; "total assets ${ }^{17}$, as a variable for firm size ${ }^{18}$; "time" measured as the number of years on the market ${ }^{19}$; "company" as a variable for the form of society (srl or SpA) $)^{20}$; "location" (North, Centre, South and Islands) ${ }^{21}$; "sector of activity" (five groups of Ateco ${ }^{22}$ code of two digit) ${ }^{23}$.In order to facilitate the reading, the detailed and complete results are provided in Appendix and we exhibit here the main outputs.

The results of our model underline two main findings. Besides the weak significant coefficient $(\mathrm{P}<0.10)$ relating to the variable "time", we found a strongly significant coefficient $(\mathrm{P}<0.01)$ relating to the "total assets" variable: SO with a higher level of total assets had also a higher level of added value, but the impact is very low.

The model demonstrates that the average level of added value in 2007 for SOwithTIP was Euros 169,355, while for SOwithoutTIP was Euros 95,341. Nevertheless, the regression model did not highlight a positive or negative impact of SOwithTIP or SOwithoutTIP on the level of added value in 2007. Flagspinoff was not a statistically significant variable in this model. In other words, the characteristic of being a

\footnotetext{
${ }^{14}$ Descriptive statistics, correlation matrix, the linear regression model and tests for multi-collinearity are described in Tables 12-16 (see Appendix).

${ }^{15}$ Additionally, it also provided a confirmation of the pertinence of our sample: all firms were actual SO.

${ }^{16}$ We measured the variable "flagspinoff" by using a binary variable which took the value 1 if the firm had an alliance and 0 otherwise.

${ }^{17}$ This variable has been calculated as total assets minus fixed assets.

${ }^{18}$ We decided to measure the firm size in terms of "total assets", because it has been not possible to have enough and reliable data on the number of employees.

${ }^{19}$ We measured the variable "time" starting from 0 if the firm was created in 2007; 1 if it was established in 2006; 2 if it was founded in 2005 , and so on.

${ }^{20}$ We measured the variable "company" with a binary variable which took the value 1 if the firm was a srl and 0 otherwise.

${ }^{21}$ We measured the variable "location" by introducing 3 dummy variables for North, Centre and South and Islands of Italy.

${ }^{22}$ Since the $1^{\text {st }}$ of January 2008 a new classification of economic activities called Ateco 2007 is in force as the single rule of classification for public administration. This new classification in Italy is published by Istat (National Institute of Statistics) and it is the national version of the European nomenclature NACE Rev. 2, established by the Regulation EC n. 1893/2006 of the European Parliament and the European Council.

${ }^{23} \mathrm{We}$ controlled for industry effects by employing 5 dummy variables for the industrial sectors of ICT, transport, biopharmaceutical, engineering, other. These variables take a value of 1 if the company is in the sector and 0 otherwise. These sectors were identified starting from the Ateco 2007 classification: we formed groups of firms with the same Ateco code of two digit. In the sector named "other" were included the few firms dealing in general in the consultancy industry and in the commerce and editor industries.
} 
SOwithTIP or not had no impact on the level of added value in 2007. This result is consistent with the questionnaire results: differences between SOwithTIP and SOwithoutTIP exist, but these differences seem to be not so marked to have an impact on the performance. SOwithTIP have more capital availability, thanks to the industrial partner support, but this characteristic is not translated in a superior performance: SOwithTIP and SOwithoutTIP have the same form of society, SOwithTIP are not strategically located in the more industrialised and fertile part of Italy, are not specifically supported by their parent institute or hosted in an incubator-science park, do not have an higher number of patents and do not show significant differences in the sector distribution and product or service orientation compared to SOwithoutTIP.

What can we assume, then? Implications of the results, the potential role of BES and suggestions for policy improvement are analysed in the following section.

\section{Discussion}

Literature pinpoints that it is difficult to persuade SO founders to be involved in a traditional partnership agreement, because of their specific characteristics and marked desire for independence (Shane, 2004). Furthermore, it underlines that integration and motivation of the SO staff and the partner team has to be achieved. Trust, interdependency between partners, frequency of communication and closeness of partners are significant elements (Sherwood, Covin, 2008; Bruneel et al. 2010; Bjerregaard, 2010; Niedergassel, Leker, 2011). Nevertheless, as underlined in general for many companies by Revilla et al. (2005) and Chen (2004), SO in particular cannot focus only on their sole internal capabilities, because they suffer gaps of managerial and business knowledge as well as a lack of financial resources and a small size (Mustar et al., 2008; van Geenhuizen, Soetanto, 2009; Batheltet al., 2010). However, our empirical analysis highlighted a self-training propensity and a perception of no lack of business competence. As a consequence, the actual articulation of SO seems more inclined towards "non"-traditional partnerships like the embeddedness in BES.

\subsection{The structuring of a business ecosystem: characteristics, governance and location}

The structuring of a business ecosystem may highlight in which extent traditional one to one industrial partnerships may be conceived not in the traditional sense, but rather in the form of a set of industrial relations between SO. Analyzing university SO in Northern Ireland, Harrison and Leitch (2010, p. 1244) underlined that the economic impact of SO "is enhanced when they are embedded in a strong local entrepreneurial ecosystem or knowledge pool". Nonetheless, from the Irish companies analyzed by Harrison and Leitch (2010) the regional ecosystem was far from munificent in terms of access to business development resources.

Niedergassel and Leker (2011) and Bjerregaard (2010, p. 106) investigated R\&D collaboration between SMEs and academia: the last one observed that "a shared cultural micro-cosmos for collaboration, which in most cases was based on tacit rather than written agreements" contributed to the lack of normative conflict between interests, goals and cultures. This "shared cultural space" can be applied in the case of SO, which share the same research origin as well as tacit knowledge, and can benefit from e-networks. In fact, Roberts (2000, p. 435) argued that the ability of ICTs to assist the transfer of tacit knowledge is restricted by 
the need for trust and mutual understanding facilitated by face-to-face relationships. But, if the parties involved "share a common social and cultural context", "they may share tacit knowledge by assimilating codified knowledge and thereby creating new tacit knowledge". To this aim, the SO phenomenon with its "knowledge" background is a useful and interesting case-study in order to investigate the Steiner (2004) question of how the need for spatial proximity can be made compatible with the need for connectivity and to tackle the problem to find ways to enlarge the geographical span of knowledge spillovers. Our empirical analysis highlighted that SOwithTIP chose a traditional industrial partner because of same interests and activities and looking for more clients and commerce. Nevertheless, the contribution to capital and the competencies provided by the partner were not so significant: the industrial partner and/or an external manager seemed not to be very important as a solution to lack of managerial competence and the regression model did not highlight an impact of SOwithTIP or SOwithoutTIP on the level of added value in 2007. Furthermore, the industrial partner did not influence the form of society as well as the sector and product or service orientation: no marked differences emerged in the comparison between SOwithTIP and SOwithoutTIP. As we already mentioned in the introductory part, these findings may suggest the importance of "non"-traditional industrial partnerships. While the literature underlines the role of industrial partnerships, one could hardly argue the singularity of SO. Therefore, we rather suggest SO demonstrate that industrial partnerships have to be conceived not in the traditional sense, but rather as a set of industrial relations between SO which constitute a virtual industrial cluster - what the literature calls "BES".

As this was already the case for a SO, "the business ecosystem concept has been used by several authors, but it still lacks a precise definition" (Peltoniemi, Vuori, 2004, p. 2; Peltoniemi, 2006, p. 10). The concept was introduced in the early 1990s by Moore (1993, p. 76) who suggested "a company be viewed not as a member of a single industry but as part of a business ecosystem that crosses a variety of industries. In a business ecosystem, companies coevolve capabilities around a new innovation: they work cooperatively and competitively to support new products, satisfy customer needs, and eventually incorporate the next round of innovations". Comparing a business's evolution path to an ecosystem can be difficult and only a few studies in the literature have attempted such a complex investigation (Peltoniemi, Vuori, 2004; Corallo et al., 2007; $\mathrm{Li}, 2009)$. Taking into consideration the evolutionary and collective dimension of industrial partnerships, several consequences arise. The main important one is probably the governance and leadership concern: "who" takes the role of the leader and orient the industrial dynamics in a community of firms. Such leadership is important because it enables all ecosystem members to invest towards a shared future of profits (Moore, 1993). A central role is played by universities, because they are an important engine of knowledge spillovers (Clarysse et al., 2011; Audretsch et al., 2012; Huggins et al., 2012; Lawton Smith, Bagchi-Sen, 2012). This is confirmed by the recent investigation in search of key obstacles to growth undertaken by van Geenhuizen and Soetanto (2009, p. 679): they recommended that "programs aimed at nurturing highly innovative spin-offs in manufacturing should include early and more substantial support, particularly access to networking with or through the university, and supporting activity of the university such as acting as launching customer and intermediary agent in export relations". A leader has to be able to direct internal 
and external changes and to manage the transformation of the business ecosystem from a random collection of elements to a more structured community. This role can be taken by intermediary institutions like not only universities but also incubators and science and technology parks. Our empirical analysis revealed that aid from the incubator/science park has been of greater importance as a solution to lack of managerial competence (11\% for SOwithTIP and $23 \%$ for SOwithoutTIP) compared to aid from an external manager (12\% for SOwithTIP and 14\% for SOwithoutTIP). And these results could be higher if science parks and incubators improved their effectiveness ${ }^{24}$.In our opinion, these structures should apply a concerted effort in order to build bargaining power and to make it uneconomical for competitors to enter. Given the fact that in a business ecosystem a firm not only has to build its standards, but also to work hard to help others to achieve their own benefits, a science park or an incubator can work in order to achieve this goal on behalf of the firms alone. The members in the ecosystem are independent, yet they co-evolve with the science parkincubator's roadmap. Business strategies at the single level become systematic cooperation and single growth becomes co-evolution ( $\mathrm{Li}, 2009)$. According to Peltoniemi (2006, p. 18), in a business ecosystem "conscious choice, limited knowledge, interconnectedness and feedback loops result in a nondeterministic, nonlinear and unpredictable future constructed by organizations". In the case of SO, mutualistic coevolution may be applied: firms develop cooperation and complementary capabilities in order to compete with a third party. The recent analysis undertaken by de Faria et al. (2010, p. 1090) corroborated that "close partners such as firms within the same group or suppliers are more effective for the development of innovation cooperation activities. Technology also plays a role, as firms from industries with higher levels of technology attach a higher value to cooperation partners".

In order to identify factors that might highlight the structuring of BES, we start from some considerations on the location.

The literature has stressed and proved the importance of geographical proximity between SO and their parent institute and science park-incubator ${ }^{25}$. Geographical proximity is a key factor for networks formation, mutual trust and cooperation (Piscitello, Sgobbi, 2004; Audretsch et al., 2012). High-tech clusters arise where knowledge is "produced", because proximity is an advantage for knowledge transmission: the variable "space" is pivotal (Krugman, 1998). The importance of trust encouraged by repeated face-to-face interactions has led Saxenian (1994, p. 161, cited in Wessner, 2009, p. 23) to observe that "paradoxically regions offer an important source of competitive advantage even as production and markets become increasingly global". Nevertheless, Kroll and Liefner (2008) in their analysis on the Chinese case, have argued that most authors agree that up to now cooperation between universities and companies remains weak. Our empirical analysis results are in line with these considerations: no specificity emerged between SOwithTIP and SOwithoutTIP about the interest of the university and the hospitality in a science parkincubator. With these considerations in mind, we suggest to go forward and link the "locally confined area"

\footnotetext{
${ }^{24}$ See, among others, Siegel et al. (2003) for the UK; Rothaermel, Thursby (2005) for the US; Colombo, Delmastro (2002), Co-author (2011) for Italy; Schwartz (2009) for Germany; Sofouli, Vonortas (2007) for Greece.

${ }^{25}$ For a comprehensive discussion on the distance between the science park and the university campus and the importance of proximity, see Link, Scott, (2006; 2007); Wessner, ed., (2009).
} 
(Kroll, Liefner, 2008, p. 302) - given by SO, the parent institute and a science park-incubator - to the advantages of the Internet and the new technologies (Co-author et al., 2009; Co-author, 2010) and therefore to the possibility to build not only "face-to-face networks" but also "e-networks". ICT technologies and globalisation reduces the importance of geography (Moore, 1996; Boschma, 2005). Steiner (2002; 2004) argued that the actual and future improvements in the ICT field will enable the development of clusters not limited to specific geographical locations. Furthermore, Porter (1998, p. 81) argued that "all formal alliances involve their own complex bargaining and governance problems and can inhibit a company's flexibility. The close, informal relationships possible among companies in a cluster are often a superior arrangement". We build on these assumptions for the SO context. This means to build a network of BES that are something more than a traditional cluster and they are not geographically limited in given areas or in the North, the Centre and the South of a country. A "bundle of similar characteristics" identifies a business ecosystem. In the case of SO these characteristics are identifiable first of all in the specificity of the "knowledge" background, in the industrial sector, the product or service orientation, the low or high capital, the national or international attitude. Communication and networking are facilitated by a similar origin: SO come from the same social context that is the research world. These firms are linked to the parent institute proximity and facilities; therefore they could find obstacles in locating in a classical cluster or industrial district in a given geographical area. And in fact our empirical analysis showed the absence of any specificity about the location of SOwithTIP and SOwithoutTIP. If we go beyond the geographical factor and "space", that should not be a boundary but an advantage thanks to the Internet and ICT potentialities, and if we go beyond the "single" university/science park strategy, we are able to make the overall extent of the phenomenon clear and map all the SO established in a given country.

\subsection{ICT-supported virtual networks and Digital Business Ecosystems}

The weakness of location influence on industrial relationship supports, therefore, the argument that geographical proximity may be substituted by ICT-supported virtual networks and communities of practice.

In recent years, we have assisted to a renewed interest of practitioners and industrial policy makers for the concept of business ecosystem. More specifically, since 2002 the concept of business ecosystem has attracted deep attention in the digital evolution because of the attempt to build a network of "digital BES" fostering the local development (Nachira, 2002; Nachira et al., 2007). The Digital Business Ecosystem represents business-to-business interactivity supported by a software platform, which should have the desirable properties of a natural ecosystem and display marked network effects. Armed with this infrastructure the ecosystem could achieve evolution, self-organization, and a self-optimizing environment (Stanley, Briscoe, 2010).The European Council held in Lisbon on March 2000 recognised the need for Europe for an exploitation of new opportunities of the economy and in particular the Internet. The building of a community that shares business, knowledge and infrastructures will affect the ways business is conducted in the future and will lead to alliances, partnerships and collaboration. Small organisations, facing difficulties to the migration to e-business, could take advantage of this evolution, but a networked organization, cooperating and sharing information and instruments could help to achieve this goal. The 
network organization linked to the flexibility that characterizes SMEs could reach positive results preserving the small dimension of this kind of firms. This is true for SO as well as for SMEs enhanced by ICT application and services to improve their efficiency and to compete with larger software houses (Peltoniemi, Vuori, 2004).

Therefore, the term Digital Business Ecosystem derives by adding "digital" (Nachira, 2002) in front of Business Ecosystem (Moore, 1996) and it refers to a socio-economic development catalysed by the use of the Internet and the ICT. Nachira emphasised the coevolution aspect of BES with their digital representations (Stanley, Briscoe, 2010), hence Digital BES (Nachira et al.,2007). "A Digital Ecosystem is essentially the distribution of desired server functionality amongst a population of nodes. Digital Business Ecosystems are a platform for a network based economy of business ecosystems, providing the necessary technical infrastructure and legal mechanisms for the creation of networked economies" (Stanley, Briscoe, 2010, p. 8 and 21).

Nachira et al. (2007, p. 7) argued that digital ecosystems are seen as even more effective at the regional rather than at the national or international scale, because common language leads to a shared understanding of reality, which leads to shared means of expression and therefore similar and interdependent technologies. "The Digital Ecosystems initiative aims at helping local economic actors become active players in globalisation, "valorising" their local culture and vocations and enabling them to interact and create value networks at the global level. Increasingly this approach, dubbed "glocalization", is being considered a successful strategy of globalisation that preserves regional growth and identity (Khondker, 2004)". According to Porter (1998; 2000, p. 32), "globalization and the ease of transportation and communication...have created the location paradox...Paradoxically, the most enduring competitive advantages in a global economy seem to be local": knowledge and relationships are among these local advantages. If we think about the universe of SO of a given "country" as the "local level", then we are able to preserve the knowledge component, the independence attitude and the potentialities of this particular kind of firms in a globalised world.

The challenge lies in developing a system in which SO can foster their knowledge potentialities and maintain some sovereignty and autonomy as well as internal control, while also engaging in a superior structure that organizes and takes into account the needs and the differences in operating procedures and practices of the single parties. In our opinion, this challenge is a set and network of industrial relations interpreted as what the literature calls "BES" either they are physical or digital.

\section{Limitations and concluding remarks}

According to Wright et al. (2004) the commercialisation of scientific discoveries through a joint venture spin-off (JVSO) has been neglected in the literature. From that extent, our research constitutes a useful and rare investigation of SO on a large and systematic basis. Of course, we need to emphasize that this study suffers from some shortcomings, but many of these limitations are common to most recent empirical 
investigations in this field ${ }^{26}$. First of all, despite the well-recognized value of studying the SO phenomenon, empirical studies on this topic are continuously constrained by the limited availability of data (Shane, 2004). Statistically, the size of our population of SO is quite significant (not far from 40\%) and well above the current sample size of empirical analyses on a national context and in line with most empirical investigations on the SO phenomenon ${ }^{27}$. Nevertheless, our analysis relied on data covered on a given time period: the SO phenomenon has attracted the attention of researchers and policy makers only in recent years. The questionnaire survey was undertaken in 2008 (January-June) and, accordingly, 2007 was the first year for which it has been possible to have complete data from Aida data bank. Furthermore, the analysis is focused on the Italian case without comparisons with the same context in other countries, but, given the inspiring results of this survey, this will be an interesting insight for future research. Similarly, in case of data availability, the role of venture capital and "non"-traditional partnerships could be an issue for further research.

Our analysis revealed that SO development displays similar figures with or without a TIP. What does this mean for SO? These are a particular kind of firm, characterized by a small size as well as management and finance gaps, but with a very strong scientific knowledge background. They need to strengthen their structure not only in order to foster in the best way the potentialities developed in the parent institute but also to grow. To this goal, we cannot take for granted that a TIP could be the best solution. Furthermore, aids from a TIP and from an external manager are not considered by SO themselves as key solutions: a selftraining propensity as well as a perception of no lack of managerial competence emerged. The main issue we developed in the paper is that facing the need for missing managerial and industrial resources, SO should simply look for "non"-traditional industrial partners. And in fact SO did not demonstrate to be specifically looking for TIP. This result suggests they rather should be encouraged to explore complementary solutions like the embeddedness in a set of industrial relations between SO themselves, constituting a virtual industrial cluster providing similar strategic assets and resources for development and performance. This set and network of industrial relations may be interpreted as what the literature calls "BES" either they are physical or digital. The development of the business ecosystem concept in the literature remains very general (descriptive) and highlights different contexts and ways to characterize it. It is therefore very difficult to apply it on a concrete way considering more general SMEs and SO. Nonetheless, it provides interesting insights to be taken into consideration. Academic distant networks and virtual industrial clusters like BES can be applied "in practice" if and only if a real willingness of focusing on this phenomenon and establishing a common framework for setting up standard conditions for SO emerges at European level. As highlighted by Moore (2003, p. 1), "like individual plants or animals, individual businesses cannot thrive alone - they must develop in clusters or economic ecosystems". Therefore, we suggest to help SO not only "to go digital" (European Commission, 2001), but also to develop in "BES" as a means of safeguarding their autonomy and

\footnotetext{
${ }^{26}$ On this topic see among others: Rothaermel, Thursby, 2005; Clarysse et al., 2007; Squicciarini, 2008; Schwartz, 2009; Fini et al., 2009; Clarysse et al., 2011.

${ }^{27}$ See, for example, Mustar, 1997; Steffensen et al., 1999; Clarysse et al., 2007;Gupte, 2007; D’Este, Perkmann, 2011.
} 
fostering their knowledge potential. To this aim, a central role should be undertaken by universities, science parks and incubators.

Few relations have been made, since now, between traditional clusters (Porter, 2000) and more distributed BES, either physical or digital, in particular considering SMEs and SO. Nonetheless, as highlighted by Corallo et al. (2007, p. 11) "small firms belonging to industrial districts are growing globally, creating loosely coupled networks of firms" and they are an example of natural ecosystems. According to Iansiti and Levien (2004, p. 70-72), "the analogy between business networks and biological ecosystems can aid this understanding by vividly highlighting certain pivotal concepts". Nevertheless, "ecosystems are still poorly understood and even more poorly managed". We went beyond this analogy in order to suggest a solution aimed at safeguarding the strength of this kind of firms and reducing their weaknesses when the "knowledge" component meets the rules of the market. The empirical analysis results (i.e. the lack of significant differences between SOwithTIP and SOwithoutTIP development and performance) confirmed the usefulness of this new way of thinking in order to improve the SO performance.

In conclusion, we can recall that the importance and the role played in general by SMEs are well known. In this context, SO are a particular kind of firm. Their very nature, emerging from scientific and research development, make them characterised by an independence attitude as well as a lack of managerial and business competence; they could build - thanks to BES - specific solutions to complete their industrial needs and to support their development. If we want to assure their growth and development and not only their survival, we need to foster all the actors involved in SO policies to work together in order to avoid individual initiatives and to favour common improvements for "knowledge" valorisation at "country" level. A renewed interest at the EU level not only in general for "(digital) BES" but also in particular for an application of this concept at the community of SO could help to achieve this goal.

\section{Appendix:}

Table 12: Descriptive Statistics: total sample

\begin{tabular}{lccccc}
\hline Variable & Observations & Mean & Std. Dev. & Min & Max \\
\hline Added Value 2007 & 98 & 124040.6 & 322388.6 & -480349 & 2134616 \\
Total assets 2007 & 98 & 466208.2 & 844899.6 & 11459 & 4124147 \\
Time & 98 & 2.744898 & 2.714266 & 0 & 12 \\
\hline
\end{tabular}

Table 13: Descriptive Statistics: SOwithTIP (flagspin-off=1)

\begin{tabular}{lccccc}
\hline Variable & Observations & Mean & Std. Dev. & Min & Max \\
\hline Added Value 2007 & 38 & 169355.2 & 401608.1 & -455639 & 2134616 \\
Total assets 2007 & 38 & 545060.8 & 982776.8 & 11459 & 3522320 \\
Time & 38 & 2.552632 & 2.606617 & 0 & 11 \\
\hline
\end{tabular}

Table 14: Descriptive Statistics: SOwithoutTIP (flagspin-off=0)

\begin{tabular}{lccccc}
\hline Variable & Observations & Mean & Std. Dev. & Min & Max \\
\hline Added Value 2007 & 60 & 95341.4 & 259937.9 & -480349 & 1272073 \\
Total assets 2007 & 60 & 416268.3 & 749255 & 12389 & 4124147 \\
Time & 60 & 2.866667 & 2.795072 & 0 & 12 \\
\hline
\end{tabular}

Table 15: Correlation Matrix

\begin{tabular}{lccc}
\hline (obs=98) & Added Value 2007 & Total assets 2007 & Time \\
\hline Added Value 2007 & 1.0000 & & \\
\hline
\end{tabular}






$* * *$ Significant at $1 \%$ statistical level

** Significant at $5 \%$ statistical level

* Significant at $10 \%$ statistical level

Table 16: Variance Inflation Factor

\begin{tabular}{llc}
\hline Variable & VIF & 1/VIF \\
\hline Biopharmaceutical & 4.10 & 0.243841 \\
ICT & 4.00 & 0.249736 \\
Engineering & 2.92 & 0.342646 \\
Centre & 1.95 & 0.512359 \\
North & 1.95 & 0.513431 \\
Total assets 2007 & 1.57 & 0.635408 \\
Other & 1.56 & 0.641031 \\
Time & 1.44 & 0.692644 \\
Company & 1.27 & 0.787964 \\
Flagspinoff & 1.08 & 0.929129 \\
Mean VIF & 2.18 & \\
\hline
\end{tabular}

\section{References}

Akerlof G. A. 1970, The Market for Lemons: Quality Uncertainty and the Market Mechanism, The Quarterly Journal of Economics, vol. 84, n. 3, pp. 488-500.

Audretsch D. B., Hulsbeck M. Lehmann E. E. 2012, Regional competitiveness, university spillovers, and entrepreneurial activity, Small Business Economics, DOI 10.1007/s11187-011-9332-9, Volume 39, Issue 3, pp. 587-601.

Bank of Italy 2008, Considerazioni finali, Assemblea Ordinaria dei Partecipanti, Roma, May 31th.

Bank of Italy 2010, Considerazioni finali, Assemblea Ordinaria dei Partecipanti, Roma, May 31 th.

Barney J. (1991), "Firm resources and sustained competitive advantage”, Journal of Management, vol. 17, n. 1, pp. 99120.

Barney J., Wright M., Ketchen D. (2001), "The resource-based view of the firm: ten years after 1991", Journal of Management, vol. 27, pp. 625-641.

Bathelt H., Kogler D. F., Munro A. K. 2010, A knowledge-based typology of university spin-offs in the context of regional economic development, Technovation, vol. 30, n. 9-10, pp. 519-532.

Becattini G., Bellandi M., Dei Ottati G., Sforzi F. 2003, From industrial districts to local development, Cheltenham, Edward Elgar.

Bertolini P., Giovannetti E. 2006. Industrial districts and internationalization: the case of the agri-food industry in Modena, Italy. Entrepreneurship \& Regional Development. 18: 4, 279-304. 
Bjerregaard T. 2010, Industry and academia in convergence: micro-institutional dimensions of R\&D collaboration, Technovation, vol. 30, pp. 100-108.

Boschma R.A. 2005 Proximity and innovation. A critical assessment. Regional Studies 391:61-74.

Breschi S. Lissoni F., Montobbio F. 2008, University patenting and scientific productivity: a quantitative study of Italian academic inventors, European Management Review, vol. 5, pp. 91-109.

Bruneel J., D'Este P., Salter A. 2010, Investigating the factors that diminish the barriers to university-industry collaboration, Research Policy, vol. 39, pp. 858-868.

Camuffo A., Grandinetti R. 2011, Italian industrial districts as cognitive systems: Are they still reproducible?, Entrepreneurship\& Regional Development, 23:9-10, 815-852.

Chapman D., Lawton Smith H., Wood P., Barnes T., Romeo S. (2011), "University enterprise: the growth and impact of university-related companies in London”, Industry\&Higher Education, vol. 25, n. 6, pp. 1-10.

Chen C.-J. 2004, The effects of knowledge attribute, alliance characteristics, and absorptive capacity on knowledge transfer performance, $R \& D$ Management, vol. 34, n. 3, pp. 311-321.

Clarysse B., Lockett A., Quince T., Van de Velde E. 2002, Spinning off new ventures: a typology of facilitating services, Institute for the Promotion of Innovation by Science and Technology in Flanders, IWT-Observatory, Innovation, Science, Technology, n. 41.

Clarysse B., Tartari V., Salter A. 2011a, The impact of entrepreneurial capacity, experience and organizational support on academic entrepreneurship, Research Policy, vol. 40, pp. 1084-1093.

Clarysse B., Wright M., Lockett A., Mustar P., Knockaert M. 2007, Academic spin-offs, formal technology transfer and capital raising, Industrial and Corporate Change, vol. 16, n. 4, pp. 609-640.

Clarysse B., Wright M., Van de Velde E. 2011, Entrepreneurial origin, technological knowledge and the growth of spinoff companies, Journal of Management Studies, doi: 10.1111/j.1467-6486.2010.00991.x, vol. 48, issue 6, pp. $1420-1442$.

Colombo M. G., Piva E. 2012, Firms' genetic characteristics and competence-enlarging strategies: a comparison between academic and non-academic high-tech start-ups, Research Policy, vol. 41, pp. 79-92.

Colombo, M. G., Delmastro, M. 2002, How effective are technology incubators? Evidence from Italy, Research Policy, vol. 31, n. 7, pp. 1103-1122.

Corallo A., Passiante G., Prencipe A. 2007, The Digital Business Ecosystem, Cheltenham, UK, Edward Elgar Publishing.

Cyert R. M., Goodman P. S. 1997, Creating effective university-industry alliances: an organizational learning perspective, Organizational Dynamics, vol. 25, n. 4, pp. 45-57.

D’Este P., Perkmann M. 2011, Why do academics engage with industry? The entrepreneurial university and individual motivations, Journal of Technology Transfer, vol. 36, n. 3, pp. 316-339.

Daraio C., Bonaccorsi A., Geuna A., Lepori B., Bach L., Bogetoft P., Cardoso M. F., Castro-Martinez E., Crespi G., de Lucio I. F., Fried H., Garcia-Aracil A., Inzelt A., Jongbloed B., Kempkes G., Llerena P., Matt M., Olivares M., Pohl C., Raty T., Rosa M. J., Sarrico C. S., Simar L., Slipersaeter S., Teixeira P. N., Eeckaut P. V. 2011, The European university landscape: a micro characterization based on evidence from the Aquameth project, Research Policy, vol. 40, pp. 148-164.

De Faria P., Lima F., Santos R. 2010, Cooperation in innovation activities: the importance of partners, Research Policy, vol. 39, pp. 1082-1092.

De Man A.-P., Duysters G. 2005, Collaboration and innovation: a review of the effects of mergers, acquisitions and alliances on innovation, Technovation, vol. 25, pp. 1377-1387.

Druilhe C., Garnsey E. (2004), “Do Academic Spin-Outs Differ and Does it Matter?”, Journal of Technology Transfer, vol. 29 , pp. 269-285.

Dutta S., Weiss A. M. 1997, The relationship between a firm's level of technological innovativeness and its pattern of partnership agreements, Management Science, vol. 43, n. 3, pp. 343-356.

European Commission 2001, Helping SMEs to go digital, Communication from the Commission, COM2001136 final.

FarnstrandDamsgaard E., Thursby M. C., (2012), "University Entrepreneurship and Professor Privilege”, NBER Working Paper No. 17980.

Fini R., Grimaldi R., Sobrero M. 2009, Factors fostering academics to start up new ventures: an assessment of Italian founders' incentives, Journal of Technology Transfer, vol. 34, n. 4, pp. 380-402. 
Franklin, S. J., Wright, M., Lockett, A. 2001, Academic and surrogate entrepreneurs in university spin-out companies, Journal of Technology Transfer, vol. 26, pp. 127-141.

Garofoli G. 1992, New firm formation and local development: The Italian experience. Entrepreneurship \& Regional Development 4: 101-25.

Garofoli G. 2002, Local development in Europe: Theoretical models and international comparisons. European Urban and Regional Studies 9: 225-39.

Geuna A., Rossi F. 2011, Changes to university IPR regulations in Europe and the impact on academic patenting, Research Policy, vol. 40, pp. 1068-1076.

Gilsing V. A., van Burg E., Romme A. G. L. 2010, Policy principles for the creation and success of corporate and academic spin-offs, Technovation, vol. 30, n. 1, pp. 12-23.

Gupte, M. 2007, Success of University Spin-offs. Network Activities and Moderating Effects of Internal Communication and Adhocracy, Kiel, Deutscher Universitats-Verlag.

Hagedoorn J., Link A. N., Vonortas N. S. 2000, Research partnerships, Research Policy, vol. 29, pp. 567-586.

Hamel G., Doz Y. L., Prahalad C. K. 1989, Collaborate with your competitors and win, Harvard Business Review, January-February, pp. 133-139.

Hannon B. 1997, The use of analogy in biology and economics. From biology to economics, and back, Structural Change and Economic Dynamics, vol. 8, pp. 471-488.

Harrison R. T., Leitch C. (2010), "Voodoo institution or entrepreneurial university? Spin-off companies, the entrepreneurial system and regional development in the UK", Regional Studies, vol. 44, n. 9, pp. 1241-1262.

Hervàs-Oliver J., Albors-Garrigòs J. 2007. Do clusters capabilities matter? An empirical application of the resourcebased view in clusters. Entrepreneurship\& Regional Development. 19: 2, 113-136.

Huggins R., Johnston A., Stride C. 2012, Knowledge networks and universities: locational and organisational aspects of knowledge transfer interactions, Entrepreneurship \& Regional Development, 24: 7-8, 475-502.

Hussler C., Picard F., Tang M. F. 2010, Taking the ivory from the tower to coat the economic world: regional strategies to make science useful, Technovation, vol. 30, n. 9-10, pp. 508-518.

Iacobucci D., Iacopini A., Micozzi A., Orsini S. (2011), "Fostering entrepreneurship in academic spin-offs", International Journal of Entrepreneurship and Small Business, vol. 12, n. 4, pp. 513-533.

Iammarino S., Sanna-Randaccio F., Savona M. 2009, The perception of obstacles to innovation. Foreign multinationals and domestic firms in Italy, Revue d'Economie Industrielle, n. 125, 1er trimestre, pp. 75-104.

Iansiti M., Levien R. 2004, Strategy as ecology, Harvard Business Review, vol. 82, n. 3, pp. 68-78.

Ingham M., Mothe C. 1998, How to learn in R\&D partnerships?, R\&D Management, vol. 28, n. 4, pp. $249-261$.

Jobber D., Saunders J. 1993, A note on the applicability of the Brurold-Comer model for mail survey response rates to commercial populations, Journal of Business Research, vol. 26, n. 3, pp. 223-236.

Kaasalainen T., Makinen S., Nasi J. 2002, Looking for company small IT-firms and partnership formation, Frontiers of E-business Research, pp. 209-226.

Khondker H. 2004, Glocalization as globalization: evolution of a sociological concept, Bangladesh e-Journal of Sociology, vol. 1, n. 2, July.

Kroll H., Liefner I. 2008, Spin-off enterprises as a means of technology commercialisation in a transforming economy Evidence from three universities in China, Technovation, vol. 28, n. 5, pp. 298-313.

Krugman P. 1998, What's new about the new economic geography?, Oxford Review of Economic Policy, vol. 14, n. 2, pp. 7-17.

Lawton Smith H., Bagchi-Sen S. 2012, The research university, entrepreneurship and regional development: research propositions and current evidence, Entrepreneurship \& Regional Development, 24: 5-6, 383-404.

Li Y.-R. 2009, The technological roadmap of Cisco’s business ecosystem, Technovation, vol. 29, n. 5, pp. 379-386.

Link A. N., Scott J. T. 2006, U.S. University Research Parks, Journal of Productivity Analysis, vol. 25, n. 1-2, pp. 4355 .

Link A. N., Scott J. T. 2007, The economics of university research parks, Oxford Review of Economic Policy, vol. 23, n. 4, pp. 661-674.

Link A. N., Welsh D. H. B. 2011, From laboratory to market: on the propensity of young inventors to form a new business, Small Business Economics, DOI 10.1007/s11187-011-9345-4, forthcoming. 
Lockett, A., Siegel, D., Wright, M., Ensley, M. 2005, The creation of spin-off firms at public research institutions: managerial and policy implications, Research Policy, vol. 34, n. 7, pp. 981-993.

Lockett, A., Wright, M., Franklin, S. 2003, Technology Transfer and Universities' Spin-Out Strategies, Small Business Economics, vol. 20, n. 2, pp. 185-200.

Lokshin B., Hagedoorn J., Letterie W. 2011, The bumpy road of technology partnerships: understanding causes and consequences of partnership mal-functioning, Research Policy, vol. 40, pp. 297-308.

Miles G., Preece S. B., Baetz M. C. 1999, Dangers of dependence: the impact of strategic alliance use by small technology-based firms, Journal of Small Business Management, April, pp. 20-29.

Mohr J., Spekman R. 1994, Characteristics of partnership success : partnership attributes, communication behavior, and conflict resolution techniques, Strategic Management Journal, vol. 15, n. 2, pp. 135-152.

Moore J. F. 1993, Predators and prey: a new ecology of competition, Harvard Business Review, vol. , n. , pp. 75-86.

Moore J. F. 1996, The death of competition: leadership and strategy in the age of business ecosystems, New York, Harper Business.

Moore J. F. 2003, Digital Business Ecosystems in Developing Countries: an Introduction, Berkman Center for Internet and Society, Harvard Law School.

Moore J. F. 2006, Business ecosystems and the view from the firm, The Antitrust Bulletin, vol. 51, n. 1, pp. 31-76.

Muller K. 2010, Academic spin-off's transfer speed-Analyzing the time from leaving university to venture, Research Policy, vol. 39, n. 2, pp. 189-199.

Mustar P. 1997, Spin-off enterprises. How French academics create hi-tech companies: the conditions for success or failure, Science and Public Policy, vol. 24, n. 1, pp. 37-43.

Mustar P. Wright M., Clarysse B. 2008, University spin-off firms: lessons from ten years of experience in Europe, Science and Public Policy, vol. 35, n. 2, pp. 67-80.

Mustar P., Wright M. 2010, Convergence or path dependency in policies to foster the creation of university spin-off firms? A comparison of France and the United Kingdom, Journal of Technology Transfer, DOI 10.1007/s10961009-9113-7, vol. 35, pp. 42-65.

Mustar, P., Renault, M., Colombo, M., Piva, E., Fontes, M., Lockett, A., Wright, M., Clarysse, B., Moray, N. 2006, Conceptualising the heterogeneity of research-based spin-offs: a multi-dimensional taxonomy, Research Policy, vol. 35 , pp. 289-308.

Nachira F. 2002, Towards a network of digital business ecosystems fostering the local development, European Commission, Discussion Paper.

Nachira F., Nicolai A., Dini P., Le Louarn M., Rivera Leon L. 2007, Digital business ecosystems, European Commission, Information Society and Media.

Niedergassel B., Leker J. 2011, Different dimensions of knowledge in cooperative R\&D projects of university scientists, Technovation, vol. 31, pp. 142-150.

Nosella A., Grimaldi R. 2009, University-level mechanisms supporting the creation of new companies : an analysis of Italian academic spin-offs, Technology Analysis \& Strategic Management, vol. 21, n. 6, pp. 679-698.

O’Shea R. P., Allen T. J., Chevalier A., Roche F. 2005, Entrepreneurial orientation, technology transfer and spinoff performance of U.S. universities, Research Policy, vol. 34, n., pp. $994-1009$.

Parrilli M. D. 2009. Collective efficiency, policy inducement and social embeddedness: drivers for the development of industrial districts. Entrepreneurship \& Regional Development. 21: 1, 1-24.

Peltoniemi M. 2005, Business ecosystem : a conceptual model of an organisation population from the perspectives of complexity and evolution, e-Business Research Center, Research Reports 18, Tampere.

Peltoniemi M. 2006, Preliminary theoretical framework for the study of business ecosystems, E:CO, vol. 8, n. 1, pp. 1019.

Peltoniemi M., Vuori E. 2004, Business ecosystem as the new approach to complex adaptive business environments, in Seppa M., Hannula M., Jarvelin A., Kujala J., Ruohonen M., Tiainen T. eds., FeBR 2004: Frontiers of ebusiness research 2004, conference proceedings of eBRF 2004, Tampere, Finland: Tampere University of Technology and University of Tampere, ISBN 9521513160, pp. 267-281.

Pezzoni M., Sterzi V., Lissoni F. 2012, Career progress in centralized academic systems: social capital and institutions in France and Italy, Research Policy, vol. 41, pp. 704-719. 
Pirnay F., Surlemont B., Nlemvo F. 2003, Toward a Typology of University Spin-offs, Small Business Economics, n. 21, n. 4 , pp. 355-369.

Piscitello L., Sgobbi F. 2004, Globalisation, e-business and SMEs: evidence from the Italian district of Prato, Small Business Economics, vol. 22, pp. 333-347.

Porter M. E. 1998, Clusters and the new economics of competition, Harvard Business Review, vol. 76, n. 6, pp. 77-90.

Porter M. E. 2000, Location, competition and economic development: local clusters in a global economy, Economic Development Quarterly, vol 14, n 1, pp. 15-34.

Revilla E., Sarkis J., Acosta J. 2005, Towards a knowledge management and learning taxonomy for research joint ventures, Technovation, vol. 25, pp. 1307-1316.

Roberts J. 2000, From know-how to show-how? Questioning the role of information and communication technologies in knowledge transfer, Technology Analysis \& Strategic Management, vol. 12, n. 4, pp. 429-443.

Rothaermel, F. T., Thursby, M. 2005, University-incubator firm knowledge flows: assessing their impact on incubator firm performance, Research Policy, vol. 34, n. 3, pp. 305-320.

Samsom K. J., Gurdon M. A. 1993, University scientists as entrepreneurs : a special case of technology transfer and high-tech venturing, Technovation, vol. 13, n. 2, pp. 63-71.

Saxenian A. 1994, Regional advantage: culture and competition in Silicon Valley and Route 128, Cambridge, MA, Harvard University Press.

Schwartz M. 2009, Beyond incubation: an analysis of firm survival and exit dynamics in the post-graduation period, Journal of Technology Transfer, vol. 34, n. 4, pp. 403-421.

Shane S. 2004, Academic Entrepreneurship. University Spinoffs and Wealth Creation, Cheltenham, UK: Edward Elgar.

Sheehan K. 2001, E-mail survey response rates: a review, Journal of Computer-Mediated Communication, vol. 6, n. 2.

Sherwood A. L., Covin J. G. 2008, Knowledge acquisition in university-industry alliances: an empirical investigation from a learning theory perspective, The Journal of Product, Innovation, Management, vol. 25, pp. 162-179.

Siegel, D. S., Westhead, P. et Wright, M. 2003, Assessing the impact of science parks on the research productivity of firms: exploratory evidence from the United Kingdom, International Journal of Industrial Organization, vol. 21, n. 9 , pp. 1335-1369.

Sofouli E., Vonortas N. S. 2007, S\&T parks and business incubators in middle-sized countries: the case of Greece, Journal of Technology Transfer, vol. 32, n. 5, pp. 525-544.

Squicciarini M. 2008, Science Parks' tenants versus out-of-park firms: who innovates more? A duration model, Journal of Technology Transfer, vol. 33, n. 1, pp. 45-71.

Stanley J., Briscoe G. 2010, The ABC of Digital Business Ecosystems, Communication Laws.

Steffensen M., Rogers E. M., Speakman K. 1999, Spin-offs from research centers at a research university, Journal of Business Venturing, vol. 15, n. 1, pp. 93-111.

Steiner M. 2002, Clusters and networks - institutional setting and strategic perspectives, in McCann P. ed., Industrial Location Economics, Cheltenham, Edward Elgar.

Steiner M. 2004, The role of clusters in knowledge creation and diffusion - an institutional perspective, $44^{\text {th }}$ European Congress of the European Regional Science Association, Porto, August $25^{\text {th }}-29^{\text {th }}$.

Van Geenhuizen M., Soetanto D. P. 2009, Academic spin-offs at different ages: a case study in search of key obstacles to growth, Technovation, vol. 29, n. 10, pp. 671-681.

van Gelderen M., van der Sluis L., Jansen P. 2005, Learning opportunities and learning behaviours of small business starters: relations with goal achievement, skill development and satisfaction, Small Business Economics, vol. 25, pp. 97-108.

Venkataraman S., Van de Ven A. H., Buckeye J., Hudson R. 1990,Starting up a turbulent environment: a process model of failure among firms with high customer dependence, Journal of Business Venturing, vol. 5, n. 5, pp. 277-297.

Wessner C. W. 2009, ed., Understanding research, science and technology parks: global best practice: report of a symposium, National Research Council of the National Academies, Washington DC, The National Academies Press, downloaded from http://www.nap.edu/catalog/12546.html

Wright M., Vohora A., Lockett A. 2004, The Formation of High-Tech University Spinouts: The Role of Joint Ventures and Venture Capital Investors, Journal of Technology Transfer, vol. 29, n. 3-4, pp. 287-310.

Wright, M., Clarysse, B., Mustar, P., Lockett, A. 2007, Academic Entrepreneurship in Europe, Cheltenham UK, Edward Elgar. 
Yasuda H. 2005, Formation of strategic alliances in high-technology industries: comparative study of the resourcebased theory and the transaction-cost theory, Technovation, vol. 25, n. 7, pp. 763-770.

Zahra S. A., George G. (2002), "Absorptive capacity: a review, reconceptualization and extension", Academy of Management Review, vol. 27, n. 2, pp. 185-203. 